CONSUMING URBAN POVERTY WORKING PAPER

\section{Characteristics of the Urban Food System in Kisumu, Kenya}

No. 05 | 2018, November

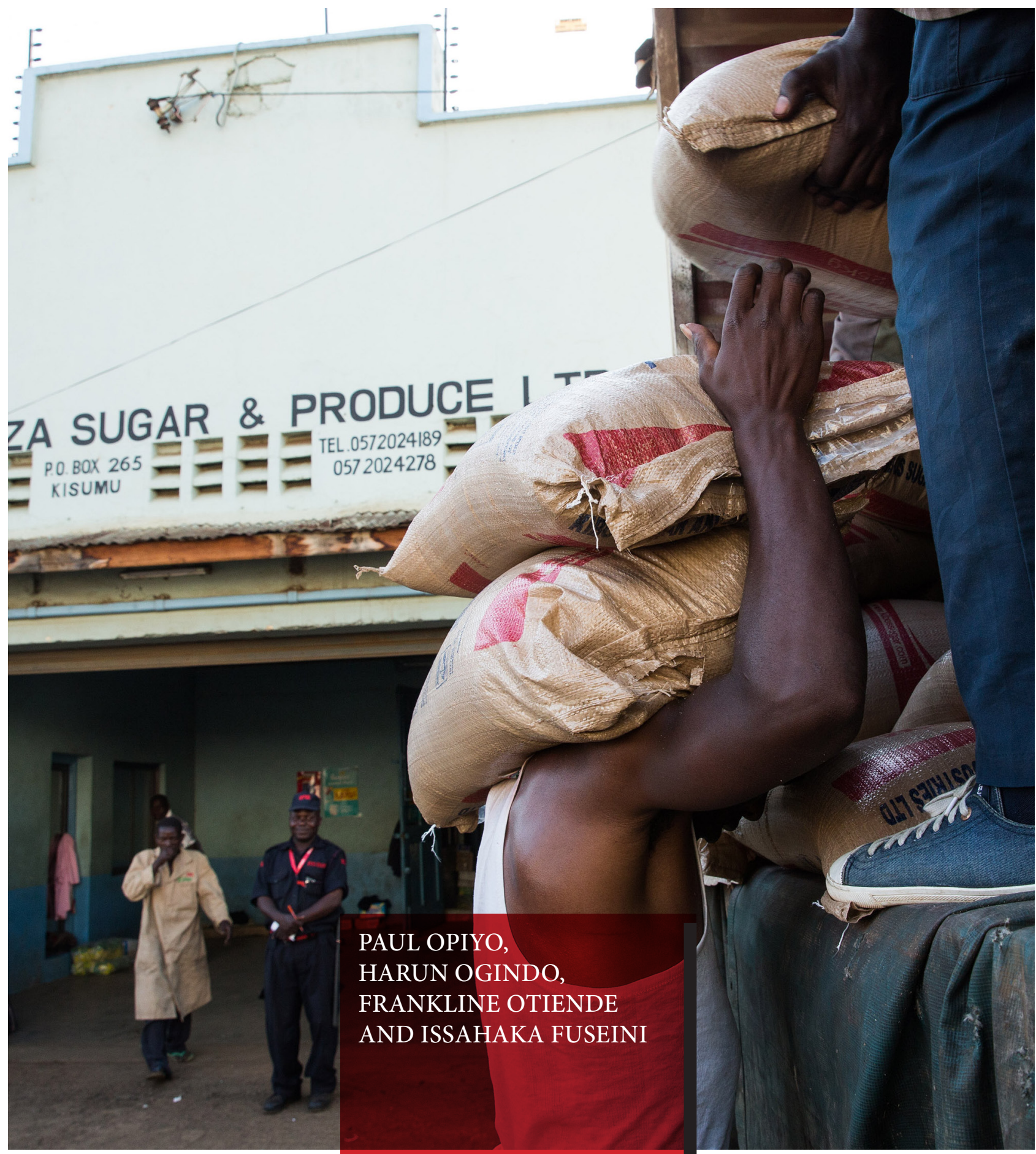

Series Editors :

Dr Jane Battersby and

Prof Vanessa Watson
Consuming Urban Poverty 


\section{Consuming Urban Poverty Project \\ Working Paper Series}

The Consuming Urban Poverty project (formally named the Governing Food Systems for Alleviating Poverty in Secondary Cities in Africa) argues that important contributions to debates on urbanization in sub-Saharan Africa, the nature of urban poverty, and the relationship between governance, poverty and the spatial characteristics of cities and towns in the region can be made through a focus on urban food systems and the dynamics of urban food poverty. There is a knowledge gap regarding secondary cities, their characteristics and governance, and yet these are important sites of urbanization in Africa. This project therefore focuses on secondary cities in three countries: Kisumu, Kenya; Kitwe, Zambia; and Epworth, Zimbabwe. The support of the Economic and Social Research Council (UK) and the UK Department for International Development is gratefully acknowledged. The project is funded under the ESRC-DFID Joint Fund for Poverty Alleviation Research (Grant Number ES/L008610/1).

(c) Paul Opiyo, Harun Ogindo, Frankline Otiende and Issahaka Fuseini 2018

Cover photograph: Samantha Reinders - for CUP

\section{Acknowledgements}

This work forms part of the Governing Food Systems to Alleviate Poverty in Secondary Cities in Africa project, funded under the ESRC-DFID Joint Fund for Poverty Alleviation Research (Poverty in Urban Spaces theme). The support of the Economic and Social Research Council (UK) and the UK Department for International Development is gratefully acknowledged (Grant number: ES/ L008610/1).

This working paper is the fifth in the CUP series available at https://consumingurbanpoverty.wordpress. com/working-papers. 


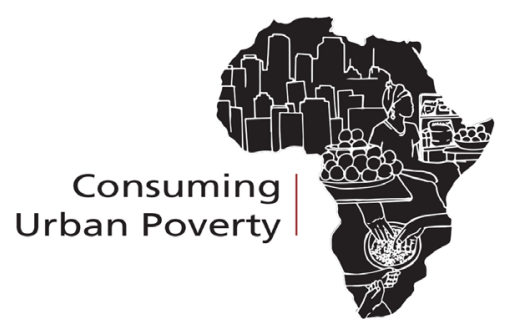

\section{Summary}

Kisumu is the third-largest city in Kenya and its status as a transport and trade hub makes it an interesting city in the context of research on secondary cities in Africa. The city's strategic location exposes it to both opportunities and challenges emanating from its complex growth and interaction with other parts of Kenya, and with neighbouring countries along the shores of Lake Victoria. This paper details three pieces of food-system-related research recently carried out in Kisumu and highlights the operating practices of food retailers, paying particular attention to informal food traders, who are traditionally viewed as unincorporated and operating from informal structures. It describes the nature and role of informal food retail in the food systems of Kisumu. The study's findings note the dominance of women in the trade, as has been reported in previous studies. It was also found that women not only dominate the landscape of informal food retail, but are also more likely to engage in it as a long-term livelihood strategy compared to their male counterparts, whose participation is relatively transient in nature. Governing urban food systems to reduce food poverty and promote livelihood security will entail mapping out these complex dynamics and embedding them into policy making and programmatic interventions to promote inclusive and sustainable urban development. Kisumu's high levels of food insecurity, compounded by low levels of dietary diversity, present a longterm development challenge for the city, the county and the wider region. The informal food economy is a key point of food access and its absence would precipitate far higher levels of food insecurity. The reverse argument also holds true: it is reasonable to assert that improving the informal food economy's operations could play a significant role in reducing food insecurity in Kisumu.

Keywords : informal food retail, informal food traders, food insecurity, food access

Suggested citation : Opiyo, Paul; Ogindo, Harun; Otiende, Frankline; and Fuseini, Issahaka (2018), Characteristics of the Urban Food System in Kisumu, Kenya, Consuming Urban Poverty Project Working Paper No. 5, African Centre for Cities, University of Cape Town. 
Summary __ iii

Keywords__ iii

Suggested citation __ iii

1. Introduction 1

2. Research approach and methods ___ 2

2.1 Design and tools __ 2

2.2 Sampling __ 3

2.3 Fieldwork and surveys___ 3

3. Results__ 3

3.1 Profile of food retailers in Kisumu __ 3

3.2 Spatial distribution and typology of informal food retail outlets __ 7

3.3 Nature of business operations___ 11

3.4 Performance ratings of informal food retail businesses __ 18

3.5 Governance and regulation _ 22

3.6 Food retail challenges in the study area___ 25

3.7 Perceived threats to viability and sustainability of informal food retail businesses__ 27

4. Policy-relevant synthesis _ 28

5. Conclusions_ 30

CUP-related reading and resources ___ 31

References _ 32 


\section{Introduction}

Kisumu is the third-largest city in Kenya and its typology could be argued to align with the corridor secondary city typology. It was therefore a useful case-study city through which to understand the nature and dynamics of urban poverty in secondary cities in Africa. The city developed from a transportation hub (railway terminus and inland port on Lake Victoria) and point of contact for the trading of agricultural produce in 1901, to become an emerging subnational administrative, trade, industrial, commercial and communications centre.

The city has grown from a small town of 32431 residents shortly after independence in 1969, to 152643 in 1979, 192733 in 1989, 322734 in 1999, and 404467 in 2009. It is estimated that Kisumu's population now exceeds 500 000. The city is strategically located within the Great Lakes region (spanning Kenya, Uganda, Tanzania, Burundi and Rwanda), and thus has regional economic importance beyond its local catchment area within Kenya. However, Kisumu reportedly has some of the highest levels of general poverty $(60 \%)$ and food poverty (53\%, compared to $8 \%$ and $39 \%$ in Nairobi and Mombasa respectively) in the country (Mireri, et al., 2007). In terms of incidence of absolute poverty, the city's proportion of $48 \%$ compares unfavourably with the national average of $29 \%$ (UN-Habitat, n.d.). The poverty situation in the city is complicated by high levels of unemployment and poor access to basic urban services: water, housing, sanitation and transport (UN-Habitat, 2006; County Government of Kisumu, 2015).

Among Kisumu's population, there was a prevalence of $6 \%$ global acute malnutrition and $2 \%$ severe acute malnutrition 2013, the former considered poor by the World Health Organisation's classification (KIRA, 2014). Understanding the nature, dimensions and patterns of these persistent and/or emergent dynamics of urbanisation on the continent, especially in secondary cities, provides opportunities for targeted policy interventions.

Kisumu's status as a transport and trade hub also makes it an interesting city in the context of research on secondary cities in Africa. The city's strategic location exposes it to both opportunities and challenges emanating from its complex growth and interaction with other parts of Kenya, and with neighbouring countries along the shores of Lake Victoria.

Earlier urban food security-specific research conducted by the African Food Security Urban Network (AFSUN) in low-income areas of 11 southern African cities, found that a high proportion of food-insecure residents obtained food from the informal sector on a regular basis. However, the informal sector was not the only source of food, with more formal supermarkets also being utilised, but less frequently. Thus any review of food security and the food system of an urban environment needs to consider the food retail environment of that city.

This paper details three pieces of food-system-related research carried out in Kisumu in 2016 and 2017. It highlights the operating practices of food retailers, paying particular attention to informal food traders, who are traditionally viewed as unincorporated and operating from informal structures. In this paper, market traders are included under the broad definition of informal. The research included mapping all formal and informal food vendors (effectively a census), which was then used to establish a sample for a more in-depth quantitative survey. This survey was supported by a reverse value chain analysis of five key foods consumed in Kisumu.

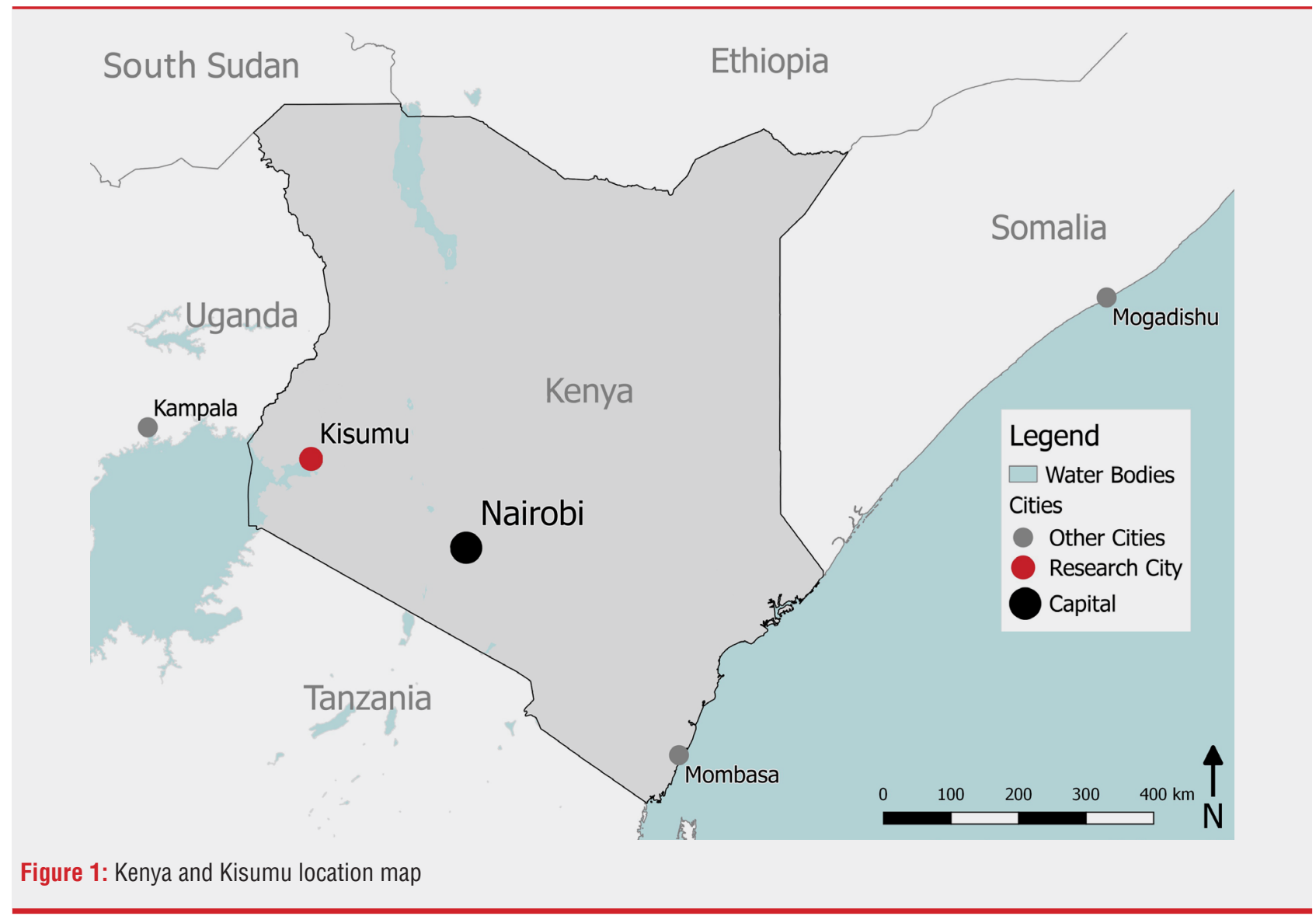

(Source: Alexander \& Park-Ross for CUP) 
Kisumu has a diverse and active food retail sector, ranging from formal supermarkets to mobile street vendors. Kisumu also has designated municipal market areas that are used by most city residents. Neighbourhoods have high levels of foodtrading activities, trading in market spaces, out of homes and at street edges. This research sought to understand all these trader typologies, enquiring into the operational, governance, logistical, livelihood and wider food-system-related dynamics of food trading in Kisumu.

The evidence presented here offers insights into a vibrant and essential component of Kisumu's economy, but also one that plays a far greater role in contributing to food security. The informal food retail system is a critical enabler of food access, particularly for the city's poor residents. The findings presented here raise significant governance and urban-planning questions, calling for greater recognition of the so-called informal food economy and its contribution to multiple economic, developmental and food-system-related aspects of daily life in Kisumu and the wider Kisumu county.

\section{Research approach and methods}

\subsection{Design and tools}

The food retail enquiry entailed two research activities: the first involved mapping food retail within the city, and the second involved a detailed survey of key sampled retail sites.

The retail mapping exercise focused on four key objectives:

- to assist in differentiating the various retail typologies and localities of trade to ensure effective coverage across the city and typologies

- to understand the key times of trade

- to fully understand the trader profile, specifically in terms of gender, and

- to enquire into the food products sold.

The mapping exercise was then used to generate the research sample for the detailed food retail survey.

The food retail survey sought to respond to the Consuming Urban Poverty (CUP) project's overarching research questions: What does the urban food system in three secondary cities in Africa reveal about the dynamics of urban poverty and its governance, and what are the lessons for generic poverty reduction? As such, the survey had a broad scope, using the food retailer and retail sites as entry points to enquire about the dynamics of urban poverty and how retailers engaged with this challenge, both in terms of food retail as a livelihood strategy and other societal goods offered (e.g. credit). A further cross-cutting theme was to use the retail survey to test governance processes, including permitting, and how this is engaged with by traders, gatekeepers and officials. Issues of product sourcing and connections to formal food systems, and questions pertaining to the nature of support for traders and the wider policy environment, were also investigated.

In conceptualising the survey, several previous framings of food retail were considered, particularly the differentiation between so-called formal and informal food retail. It was a distinct strategy of the survey to avoid the exclusion of any possible trader or store as a result of such differentiation. However, differentiation was regarded as critical in the wider framing of the urban food trade, particularly of so-called informal traders. Key information included:

- years in specific type of trade (informal food trader, shop owner, etc.)

- years trading at store/outlet

- registration or permit status, including a review of the range of permits held (personal and store health certificates, etc.)

- number of employees

- estimated annual turnover

- taxes and other levies and duties paid

- nature of incorporation

- connections to other food-system actors.

These questions were extracted from a range of literature and policy framings of the so-called informal food sector; more specifically, a framing that described what the formal food retail sector does and what another component of the sector does not do, practice or comply with. Some delineations between socalled formal and informal food traders are explicitly detailed as policy suggestions or for data-recording purposes. For example, according to the International Conference of Labour Statisticians (ICLS), the so-called informal sector refers to employment and production that takes place in unincorporated, small or unregistered enterprises (e.g. less than five employees). Further, the ICLS defines informal employment as employment without social protection through work both inside and outside the informal sector, and the informal economy as all units, activities and workers so defined and the output from them (ILO, 2003).

Defining the actors involved in the food retail sector and attempting to capture some of the traders' defining features, specifically seeking to assess how their actual trading activities aligned with CUP's poverty thematic, required another layer of questions in the survey. The hope was that these questions would provide more detail and enable further interrogation into the nature of the operators and traders.

\subsubsection{Process}

A consultative process was applied in generating the two food-retail research components. Firstly, the different survey components were discussed and agreed on at an initial stakeholder workshop attended by the core project members from all cities. Later, the typologies and specific food and legislative components of the survey were discussed at a second consultative workshop in each city. These consultative workshops were attended by a broad group of stakeholders, including the city partner teams and civil society participants. The survey was formally designed and then reviewed by each of the city partner teams. Post-review, changes were made to the language and framing of the questions, and context-specific food types, trading names and permit types, among other criteria, were included in the individual country surveys. Following these changes, the country partners convened a training session for prospective enumerators.

The surveys were conducted using hand-held tablets and open-source software. Although the survey tools provided the opportunity to ask the questions in several local dialects, all partners chose English as the survey's main language. However, as different local languages are used in and across the research sites, it was agreed that the enumerators should, where necessary, translate specific questions informed by local colloquial and 
contextual nuances. The process of building understanding was essential, enabling the greater participation of enumerators and a sense of collaborative engagement.

\subsection{Sampling}

The food retail survey applied purposive sampling of key retail outlets across selected areas in the city. The survey was done in Nyalenda, one of the largest informal settlements in the city; Jubilee Market, the main municipal market; Kibuye Market, the largest market in the city; and Oginga Odinga Street, the main street in the central business district.

In the first stage, between 30 May and 10 June 2016, all food retail outlets in the areas were enumerated and mapped (as part of the retail mapping exercise):

\begin{tabular}{ll}
\hline Nyalenda informal settlement & $30-31$ May 2016 \\
\hline Oginga Odinga Street & 2 June 2016 \\
\hline Jubilee Market & 2 and 7 June 2016 \\
\hline Kibuye Market & $8-10$ June 2016
\end{tabular}

The census estimated the daytime population of food retailers in the selected areas to be 2167 . It is worth noting that the population of food retailers may vary at different times, but for security reasons the census was carried out during the day.

The second stage involved selecting a sample of the enumerated and mapped food retailers for a more detailed, georeferenced survey. The sample size was determined as follows:

1. For the population of 2167 food retailers, and allowing for a margin of error of $5 \%$ at $95 \%$ confidence level, the sample size required was 327 .

2. Field testing the survey tool (conducted on Bank Street, close to Oginga Odinga Street) and the mapping exercise confirmed that more than $90 \%$ response rate was achievable, which meant that at least 363 food retailers needed to be approached to take part in the survey.

3. To be certain of obtaining 327 valid responses, and to capture the various determinants (a comparison of gender, store typology, etc.), the target was adjusted upwards to 551 respondents.

4. The targeted 551 respondents were distributed proportionately across the selected study sites as shown in Table 1 .

Table 1: Distribution of food retail survey respondents
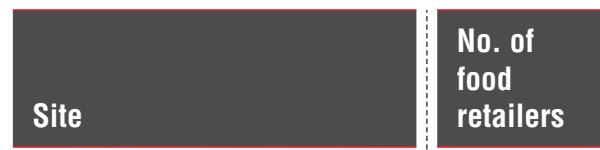

No. of food retailers

Nyalenda informal settlement retailers interviewed

\begin{tabular}{l:l:l}
\cline { 2 - 2 } Oginga Odinga Street & 129 & 33 \\
\hline Jubilee Market & 413 & 100 \\
\hline Kibuye Market & 640 & 187 \\
\hline Total: & 2167 & 551 \\
\hline
\end{tabular}

\subsection{Fieldwork and surveys}

The field work was conducted between 13 September and 3 October 2016. Fourteen enumerators and two supervisors took part in the exercise, under the guidance of researcher leaders. The surveys were completed, submitted and reviewed by the supervisors on a daily basis, checking for completeness and accuracy, before uploading on the web-based platform. The process involved an in-depth survey into various key food system and food retail operating processes, and the retail environment. A total of 551 completed questionnaires were collected as part of the survey.

\section{Results}

\subsection{Profile of food retailers in Kisumu}

Three characteristics of food retailers are reported in this section: respondents' gender and age, ownership, product mix, number of dependent household members, and years of operation.

\subsubsection{Gender and age}

The research indicated that retail space was dominated by women. Over $70 \%$ of all sampled traders were women, of which a very high proportion (about 74\%) were aged between 18 and 50 years. The age-gender distribution of respondents becomes clear when the two are compared (Figure 2). Males and females seem to enter into food retailing aged 18 years. Although males and females enter the food retail business almost at the same time, male participation peaks earlier in their lives, between the ages of 19 and 35, whereas female participation peaks between the ages of 36 and 50. The evidence in Figure 3 indicates that females not only dominate the food retail business, but also stay longer in it, through to old age, suggesting a permanent livelihood activity rather than temporary, survivalist engagement (Skinner and Haysom, 2016). Very few males participated in the food retail business between the ages of 51 and 60 , with no males over 60 years. In contrast, female participation continued, even when they were aged 60 years and older. This may also emphasise the traditional roles played by women in Kenyan communities in food handling and preparation, compared to men who participate in certain aspects of the food-production process (e.g. primary land preparation).

The differences between the levels of women and men active in food retail businesses are attributable to three reasons:

- Gendering of food practices: in Kenya, and specifically in the Kisumu region, tradition regards food provisioning, preparation and marketing as a woman's role.

- Dual retail and household care roles: women generate income as an additional benefit as they work as food vendors in their own neighbourhoods while looking after their children.

- Gendering of resource access: in Kenya, traditionally women have not enjoyed the same levels of access to capital as men.

The combination of limited sources of capital and the low level of capital required to start an informal business, makes informal food retail a deliberate choice. For these reasons, it is suggested that, for men, food retail is a temporary livelihood entry point rather than a permanent vocation. 


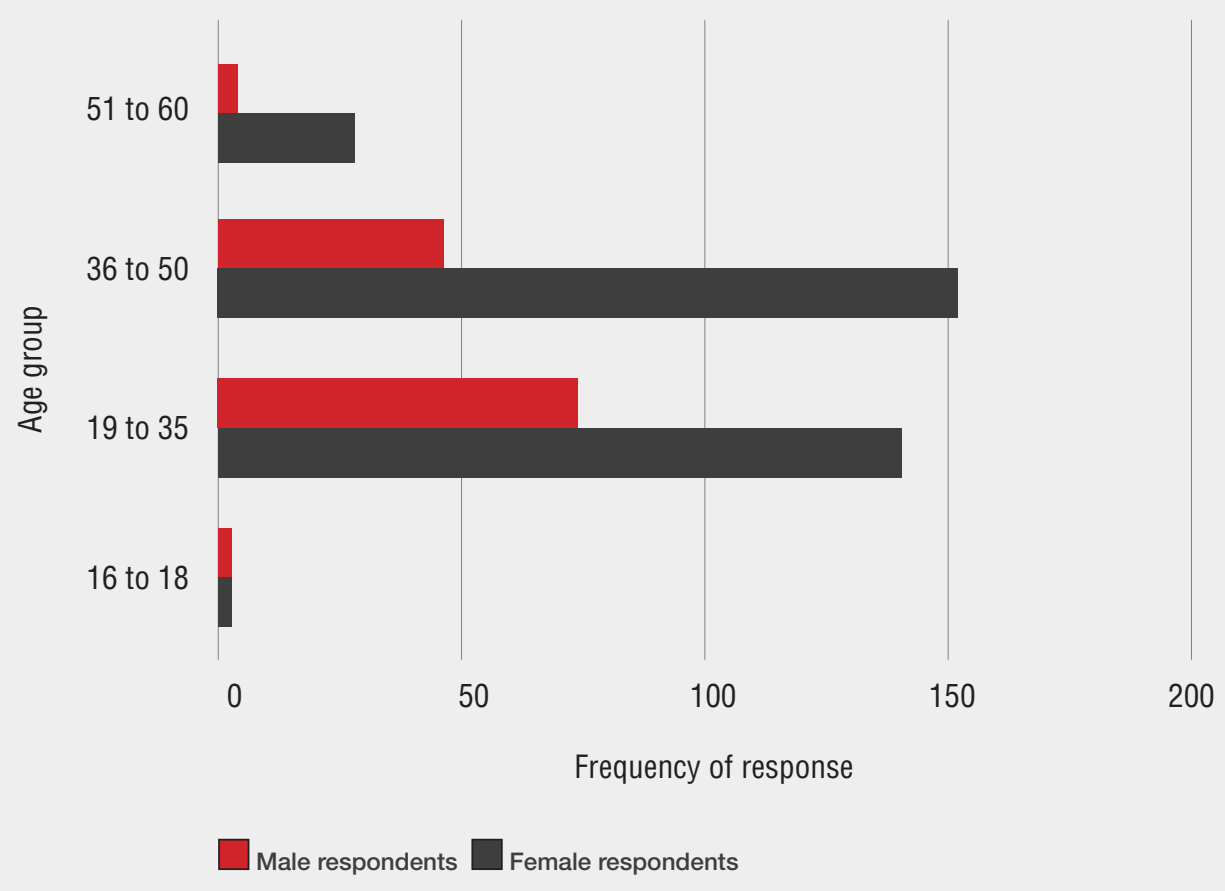

Figure 2: Age-gender of food retailers in Kisumu sample $(n=551)$

A related issue is the number of years that respondent food retailers spend in the business. The majority of respondents indicated that they had been in business for 3-5 years, but there is considerable participation beyond 5 years (Figure 3 ). However, there were variations along gender lines. Overall, the distribution reflects female dominance in the food retail trade and longevity of participation. While males and females spend 3-5 years in the retail business, the net number of females who participate in the retail business for $6-10$ years and above 10 years is more than twice and more than four times that of male participants respectively. This reflects the earlier observation that male participation in the retail trade is short-lived.

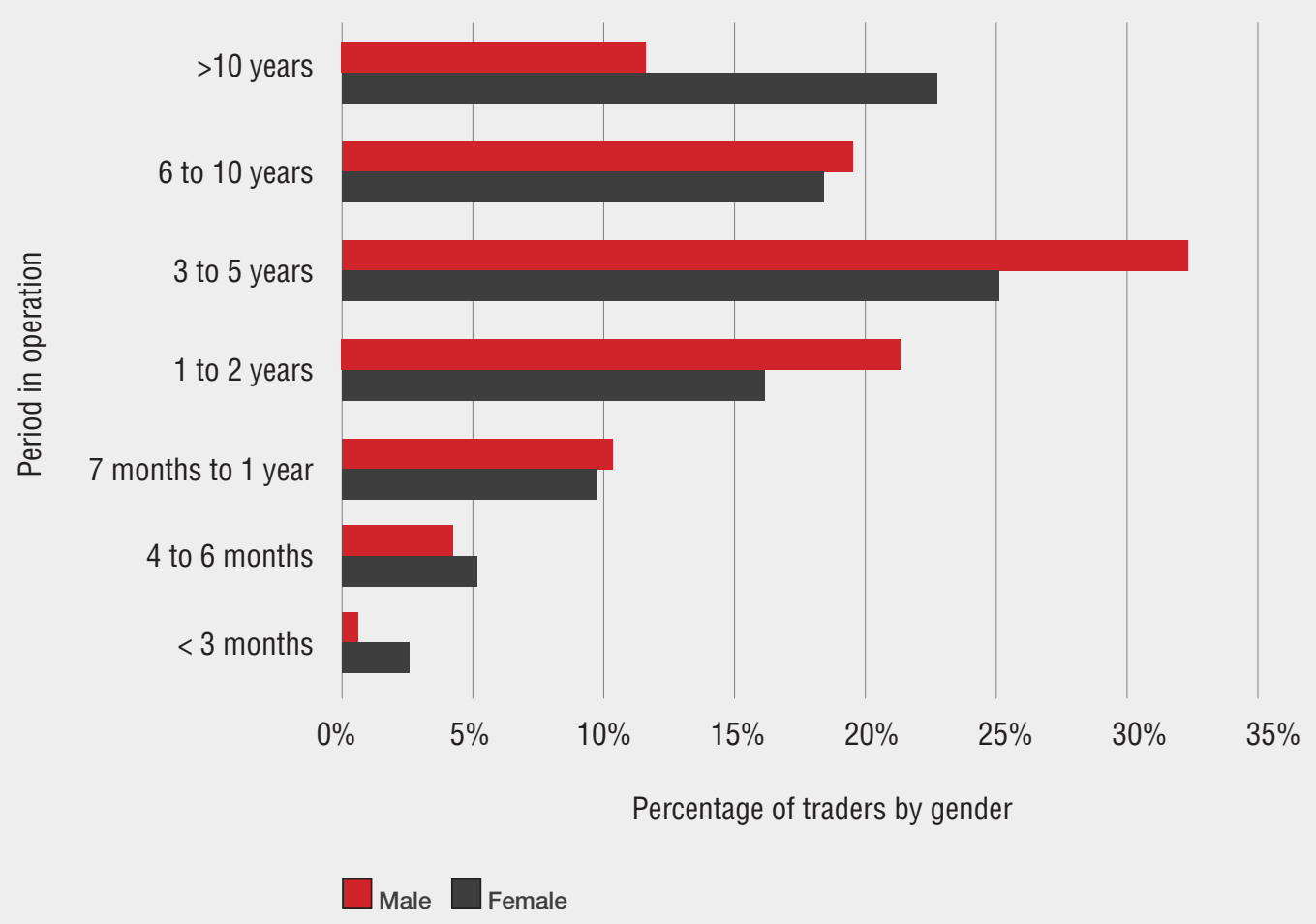

Figure 3: Period of operation as a proportion of total traders by gender $(n=551)$ 
However, it may also reflect gender-based livelihood specialisation. There is evidence of gender-based specialisation in informal retail being informed by product type, where food is one such product type (FAO, 2003). Caution is required when making broad generalisations about gendered roles in food retail as context and culture need to be considered. In West Africa, women control a greater part of food retail, while men specialise in the preparation and distribution of grilled meat, and in Dar es Salaam, Tanzania, women largely operate food retail outlets, whereas their male counterparts deal mostly in luxury goods (FAO, 2003). A 10-city study by Women in Informal Employment: Globalizing and Organizing (WIEGO) also found evidence of possible gender-based specialisation in food retail where, among informal street vendors, women were twice as likely to sell fruits and vegetables as men (Roever, 2014). In contrast, food retail activities are dominated by men in Kolkata, India (FAO, 2003). The findings of this study do, however, confirm gender-based specialisation in food retail in Kisumu, which means governing the food systems for inclusive and pro-poor urban development requires attention to these dynamics.

It is worth highlighting that there are distinctly gendered roles evident even within the broad category of food trade, when the operator's gender is compared with the store typology. In the supermarket sector, although the sample is small, most operators are male. The same gendering applies to grinding mills, traditionally an industrial job. However, market-stall operators and street vendors are predominantly female. When the profiles of store typologies are considered, those that could be considered particularly vulnerable to rent extraction and the actions of middle men are operated by female operators.

Female operators are active in retail trade, especially informal trade, for significant periods. We argue that these operations are not as transitory as some informal sector narratives may suggest, particularly when it comes to stores operated by women. The gendered nature of store holding could offer some insights into gender-related ownership profiles. Work in butcheries and grinding mills is traditionally viewed as men's work, a finding confirmed in Kisumu. As these businesses generally require greater start-up capital (mostly for equipment), this could mean that they are funded externally and then operators are recruited to manage them. Therefore, context may be a relevant factor.

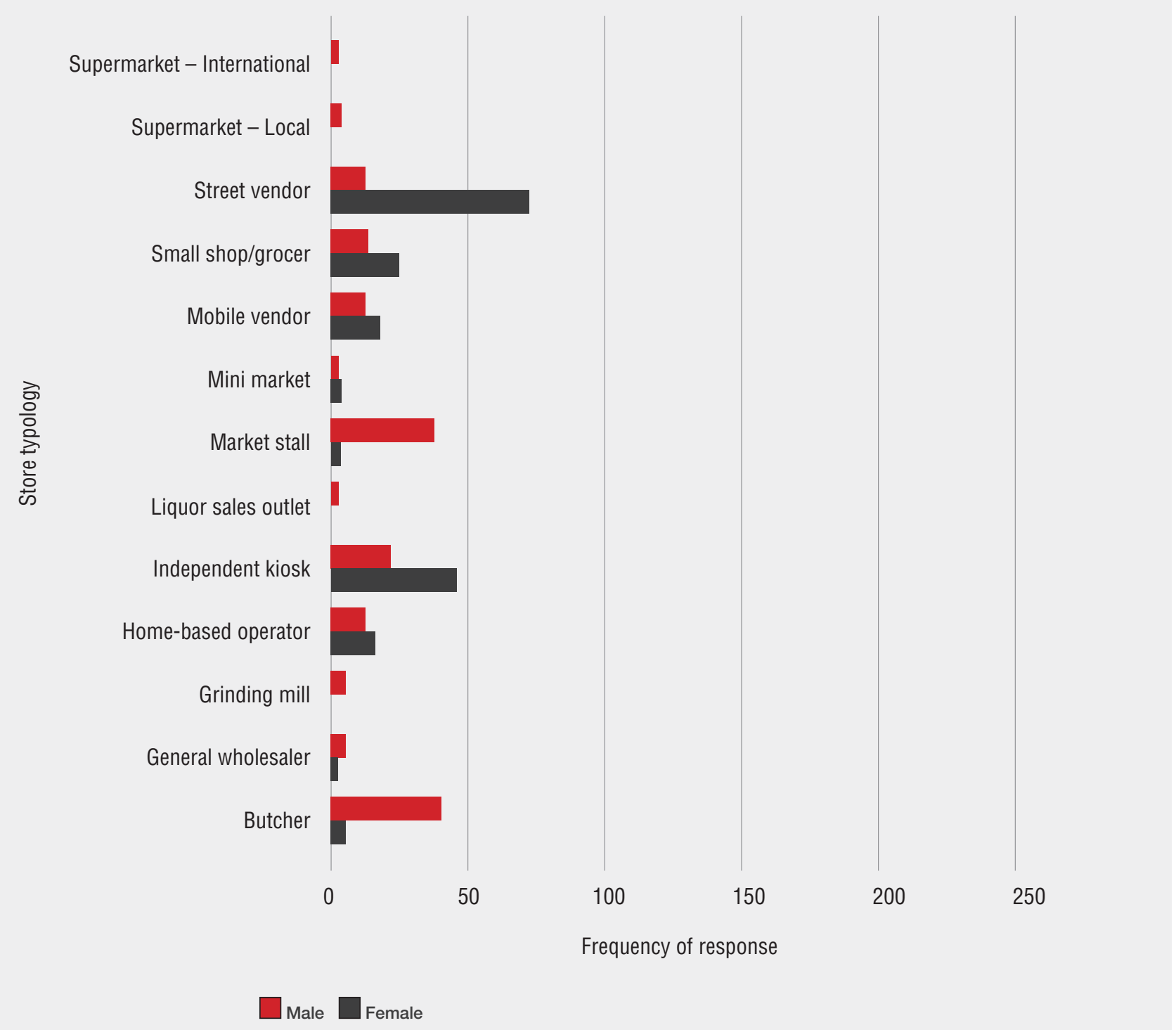

Figure 4: Gender of store operator by store typology $(n=551)$ 


\subsubsection{Ownership}

Ownership of food outlets is another feature that may help to explain food retail business dynamics. An overwhelming majority of retail operators questioned (90\%) owned the businesses they ran. Female owner-operators predominated the overall proportion of ownership at 90\%, while male owner-operators totalled a little over 80\% (Figure 5). WIEGO's 10-city study found slightly different levels of ownership among men (97\%) and women (95\%). However, the WIEGO study considered the informal sector generally, compared to the focus on the food retail subsector of this study. This aligns with the findings of Herrera, et al. (2012), who contend that, while it is often argued that women dominate the informal food trade sector, particularly the most precarious jobs within the sector, in some cities it is dominated by men.

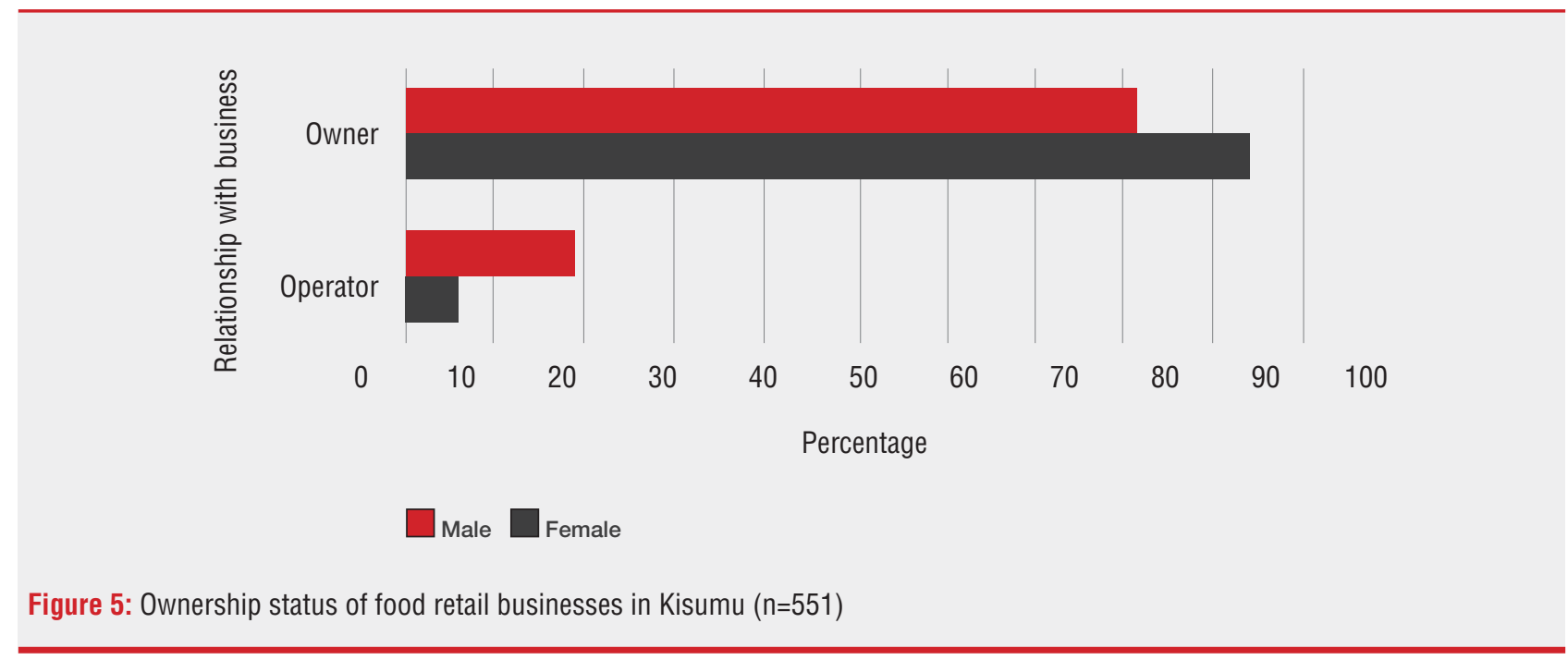

The dominance of women in food retail in Kisumu resonates with the larger picture of informal economic activities being disproportionately populated by women in many sub-Saharan African countries (Herrera, et al., 2012). In sub-Saharan Africa, 'where three out of four people are unofficially employed, the nonagricultural informal sector creates employment opportunities for $92 \%$ of women, compared with $71 \%$ of men. Out of those who work in the informal sector, $60 \%$ are women' (ECA, 2010: p. 151). The United Nations Economic Commission for Africa further asserts:

Undoubtedly, women control the most efficient and dominant forms of the economy - the informal sector - and in the final analysis they are best-suited to coping with economic crises and making contributions that far exceed their share of the population of sub-Saharan Africa. All the women in the informal sector in Africa go beyond the purely economic requirements of their trade when it comes to strategies adopted to initiate, control or strengthen their trading activities..., for they also ensure household food security and mitigate harmful economic and social effects.
While an own-account style of management is common among male and female informal businesses, women tend to engage less paid labour in running their businesses. Table 2 follows the trends observed elsewhere in the informal sector. In general terms, most stores are owner-operated and most are of a size where the employment of additional staff is unviable. Some extra staff may be used on busy trading days as casual staff but, again, the number remains small. When extra support is required, the main option is to use family members, although this is the practice of just over one-third rather than all store operators. The overly positive ECA statement above masks the reality of needing to trade to survive, which is highlighted by a respondent: 'You are either in as owners or they are out' (Respondent C, 20 September 2016). Many informal businesses remain marginal. Given the nature of this study it was not possible to ascertain how many traders had ceased to trade or had gone out of business, but most businesses are marginal and the food vendor typologies predominantly operated by women are generally more vulnerable when compared to the typologies operated by men.

(ECA, 2010: p. 152).

Table 2: Categories of labour employed by food retailers in Kisumu $(n=551)^{1}$

\begin{tabular}{l} 
Between 1 and 5 \\
\hline Between 6 and 10 \\
\hline 11 and above \\
None \\
\hline
\end{tabular}

\begin{tabular}{|l|} 
Permanent \\
\hline $5.26 \%$ \\
\hline $0.73 \%$ \\
\hline $1.09 \%$ \\
\hline $92.92 \%$
\end{tabular}

\begin{tabular}{|l|}
\hline Casual \\
\hline $15.25 \%$ \\
\hline $0.73 \%$ \\
\hline $1.09 \%$ \\
\hline $82.94 \%$ \\
\hline
\end{tabular}

\begin{tabular}{l} 
Seasonal \\
\hline $3.27 \%$ \\
\hline $0.73 \%$ \\
\hline $0.36 \%$ \\
\hline $95.64 \%$
\end{tabular}

\section{Family}

Spouse: $18.10 \%$

Children: $8.80 \%$

Relatives: $9.2 \%$

No family member: $63.9 \%$

\footnotetext{
${ }^{1}$ Casual staff were staff who worked for a specific operator on a regular basis for a few days, at month end or on one of the business trading days in a week.

Seasonal staff were staff who were employed to assist at the store, but only at seasonal peaks (climatic, cultural), when extra support was needed.
} 


\subsection{Spatial distribution and typology of informal food retail outlets}

This section presents the spatial distribution and typologies of informal food retail outlets in the study area.

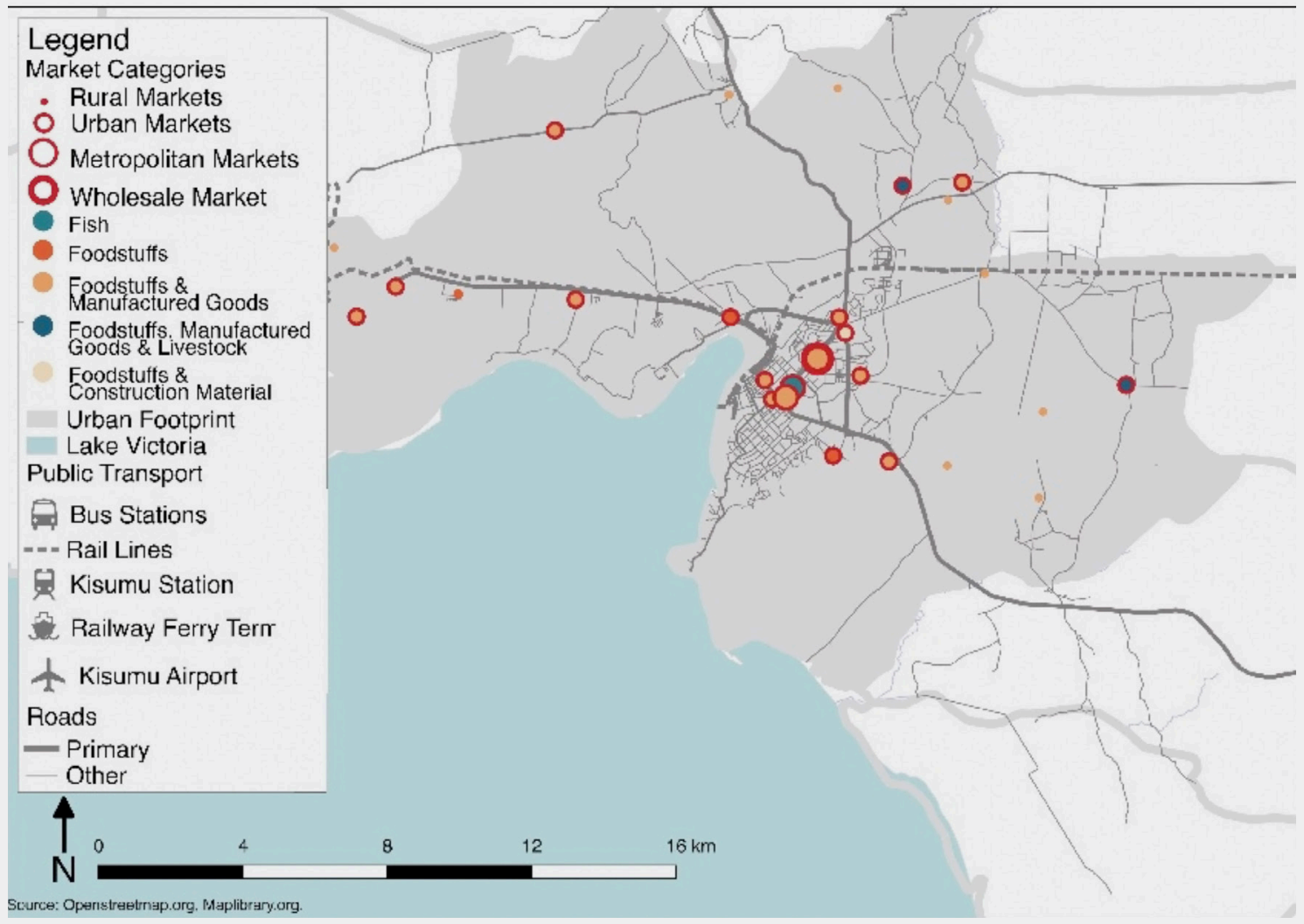

Figure 6: ISUD map showing distribution of designated markets in Kisumu (Kisumu ISUD Plan, 2013).

\subsubsection{Location of food retail outlets}

The spatial distribution of food retail outlets in Kisumu is illustrated in Figure 6, including markets and trading areas designated and managed by the municipality. A deliberate survey approach was applied to two such markets, a key street with a high density of trade, and one poor neighbourhood. For this reason, almost half (48\%) of all food retail outlets surveyed were located in municipality-approved markets. These traditional markets have market stalls, with rows designated for specific products (vegetables, fish, fruits, cereals, etc.). However, a significant percentage of food retailers were located near or adjacent to these markets, outside the designated spaces. Other traders were located in other non-designated areas of the city. Trading in close proximity to markets may be taking place because the markets have not developed in parallel to the increase in demand for this form of livelihood (informal/formal food retail businesses), which has been exacerbated by slow growth in formal and informal employment opportunities. There is also a need to be strategically located at points of high human traffic, convenient for potential clients. The food retailers outside the traditional markets included $32 \%$ on the street edges, $9 \%$ in stand-alone shops and 3\% in unapproved market spaces. Unapproved market spaces are informal markets that have grown spontaneously and are recognised by residents, but not designated as such by the city authorities. When the outlets at street edges, mobile stores, stand-alone shops, house stores and those occupying unapproved spaces are considered together, it emerges that about $50 \%$ of food retail outlets exist outside of the formally zoned markets. Reasons for this distribution are discussed in the following section. Figure 7 on the following page details the areas where food retail outlets were surveyed. 


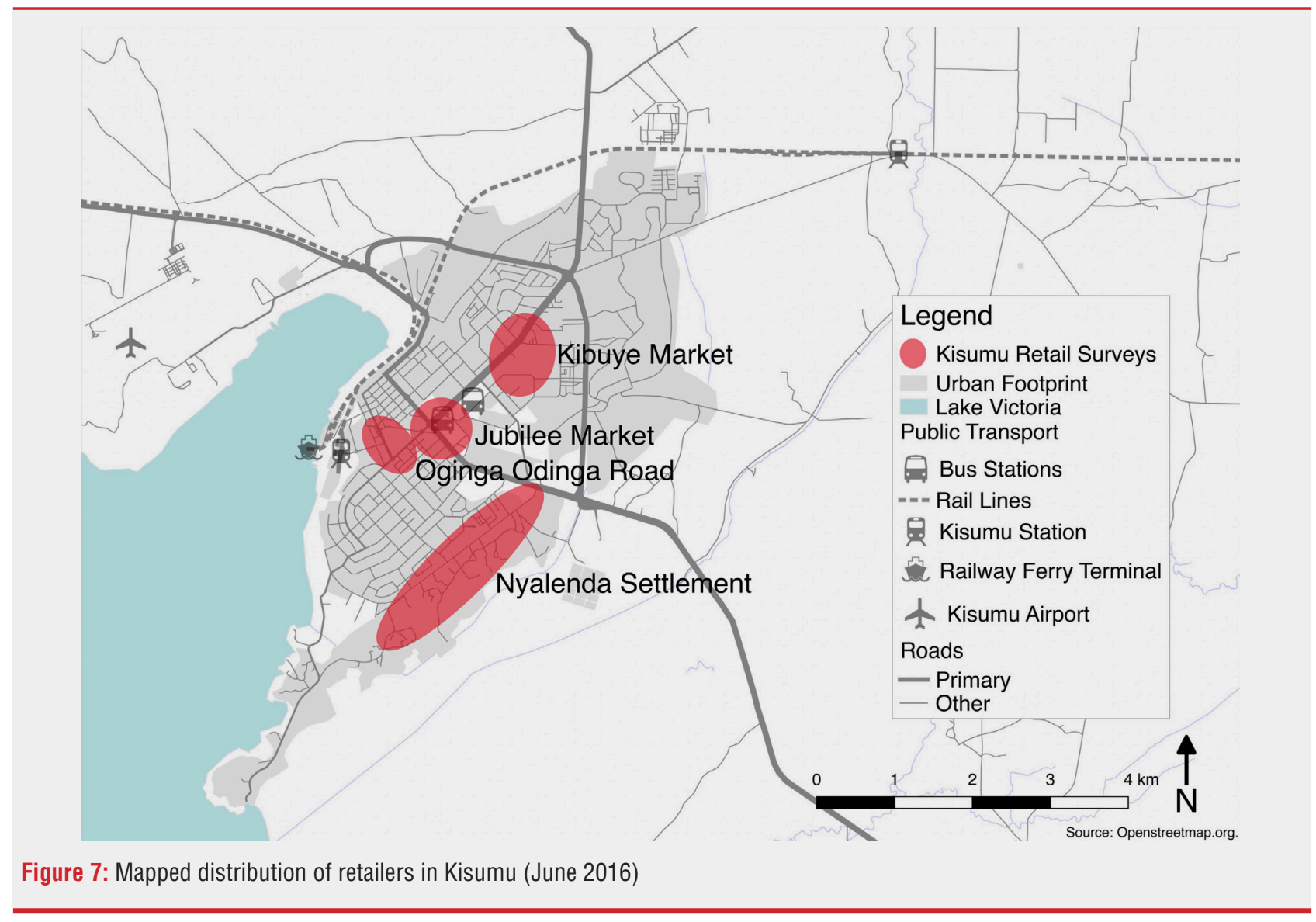

Figure 7: Mapped distribution of retailers in Kisumu (June 2016)

\subsubsection{Reasons for store location}

The reasons for traders making use of a specific trading location were explored in two ways: firstly, retailers were asked about what determined their store locations; and secondly, they were asked what motivated clients' patronage of their outlets. These two questions were asked in an attempt to understand the drivers of spatial distribution of food retail outlets, but from slightly different perspectives. The first concerned a somewhat theoretical reasoning, including opportunities accorded by economics, regulation and other spatial attributes. The second was interested in pragmatic or actual underpinnings (passing traffic, proximity to clients, etc.) influencing the location of food retail activities on the basis of practical demand-supply dynamics. Thus, the two sides of looking at the locational determinants of food retail outlets are not mutually exclusive.
(Source: Alexander and Park-Ross for CUP)

The determinants of food retail outlet location are indicated in Figure 8 . Having access to a permanent outlet and opportunity were ranked highest (28\%) and second highest (26\%) respectively. Collectively, economic-related reasons (economics, affordability and opportunity) had significant influence on the location of informal food retail outlets (598 of the 1000 responses). This high ranking of economic factors corroborates responses given by respondents to a question about the principal reasons for starting up an informal food retail business: economic opportunity, never been employed/needed a livelihood, loss of formal job, and death of spouse/breadwinner. 


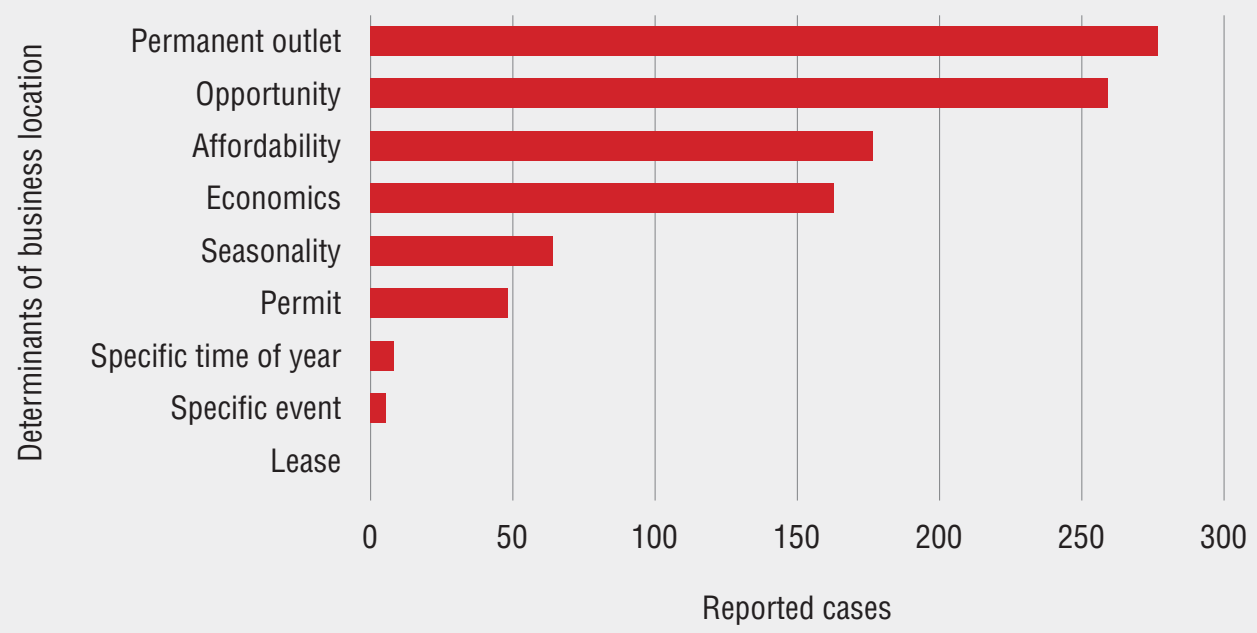

Figure 8: Determinants of food retail outlet location (multiple-response question) ( $n=1000)$

The availability of a permanent outlet, affordability, specific events and lease seem to be much easier to associate with location than other determinants that may be peripheral and due to nonlocational factors. Regulation, represented by a 'permit' or 'lease', was not considered very important in the decision where to locate an informal food retail outlet. Perhaps regulation does not matter as much as the motivation to provide vital services to clients wherever they may need these services?

\subsubsection{Reasons for clients' patronage of informal food retail outlets}

Market operators were asked to offer an opinion on why their informal outlets were patronised by clients. Retail operators provided several reasons (Table 3), but only those factors that have direct bearing on the siting of retail outlets will be discussed here. Other factors will be discussed later in this paper. Proximity to clients' neighbourhood and passing traffic (about $47 \%$ each) were cited among the most important reasons why clients patronised informal food retail outlets, alongside commuting to and from home and public transport terminals.

Table 3: Surveyed respondents' perception about reasons for the patronage of their food retail outlets (multiple-response question) ( $n=1800$ )

\begin{tabular}{|c|c|c|c|c|c|c|c|c|}
\hline & House & Mall & $\begin{array}{l}\text { Market: } \\
\text { illegal/ } \\
\text { unapproved }\end{array}$ & $\begin{array}{l}\text { Market: } \\
\text { zoned/ } \\
\text { approved }\end{array}$ & $\begin{array}{l}\text { Mini mall/ } \\
\text { shopping } \\
\text { precinct }\end{array}$ & $\begin{array}{l}\text { Mobile } \\
\text { store }\end{array}$ & $\begin{array}{l}\text { Stand- } \\
\text { alone } \\
\text { shop }\end{array}$ & $\begin{array}{l}\text { Street } \\
\text { edge }\end{array}$ \\
\hline $\begin{array}{l}\text { From } \\
\text { neighbourhood }\end{array}$ & 10 & 4 & 14 & 104 & 6 & 7 & 37 & 75 \\
\hline Passing traffic & 2 & 4 & 7 & 123 & 5 & 8 & 21 & 86 \\
\hline $\begin{array}{l}\text { On way to work/ } \\
\text { home }\end{array}$ & 2 & 2 & 6 & 80 & 3 & 3 & 16 & 63 \\
\hline $\begin{array}{l}\text { On way to or from } \\
\text { public transport }\end{array}$ & 1 & 2 & 1 & 85 & 4 & 4 & 11 & 55 \\
\hline $\begin{array}{l}\text { Looking for a } \\
\text { specific product }\end{array}$ & 0 & 3 & 1 & 68 & 1 & 5 & 4 & 15 \\
\hline $\begin{array}{l}\text { Convenience (one } \\
\text { stop shop) }\end{array}$ & 2 & 4 & 0 & 22 & 2 & 0 & 2 & 23 \\
\hline $\begin{array}{l}\text { Sole supplier/using } \\
\text { you as wholesale }\end{array}$ & 0 & 1 & 1 & 10 & 0 & 0 & 1 & 2 \\
\hline Price & 3 & 4 & 3 & 96 & 1 & 6 & 16 & 48 \\
\hline Owe you money & 0 & 0 & 1 & 6 & 0 & 0 & 0 & 4 \\
\hline Service excellence & 4 & 5 & 5 & 158 & 6 & 6 & 19 & 65 \\
\hline Offer credit & 0 & 2 & 3 & 58 & 0 & 1 & 3 & 24 \\
\hline Quality of products & 3 & 3 & 1 & 138 & 2 & 5 & 21 & 62 \\
\hline Total & 27 & 34 & 43 & 948 & 30 & 45 & 151 & 522 \\
\hline
\end{tabular}


The locational attributes of informal food retail outlets, including the stated reasons for clients' patronage, speak to the role played by informal food retailers in promoting access to food and food security in urban settings. The spatially explicit reasons for clients' patronage of informal food retail outlets reflect the spatial distribution of retail outlets. Street-edge, stand-alone, mobile and homebased shops, and to some extent the unapproved markets, all function to serve the food needs at the neighbourhood level, as well as regular commuters and those in passing traffic. In doing so, the informal food retail subsector fills an important gap regarding spatial access to food, thus countering notions of food desert. In other words, the food needs of the non-motorised public (often the poor) are served conveniently by these informal food retail outlets located in close proximity to their customers. This, together with client-centred business operations, endears retailers to their clients in a mutually beneficial relationship. Ignoring these attributes has implications for the current governance approaches to the informal sector, particularly the relocation of prime markets and the movement of traders to so-called trader malls.

\subsubsection{Typology of informal food retail outlets}

Informal food retail outlets were classified into 13 categories, the typological distribution of which is indicated in Figure 9. The presence of local and international supermarkets in Kisumu's food retail landscape is less than $1 \%$.

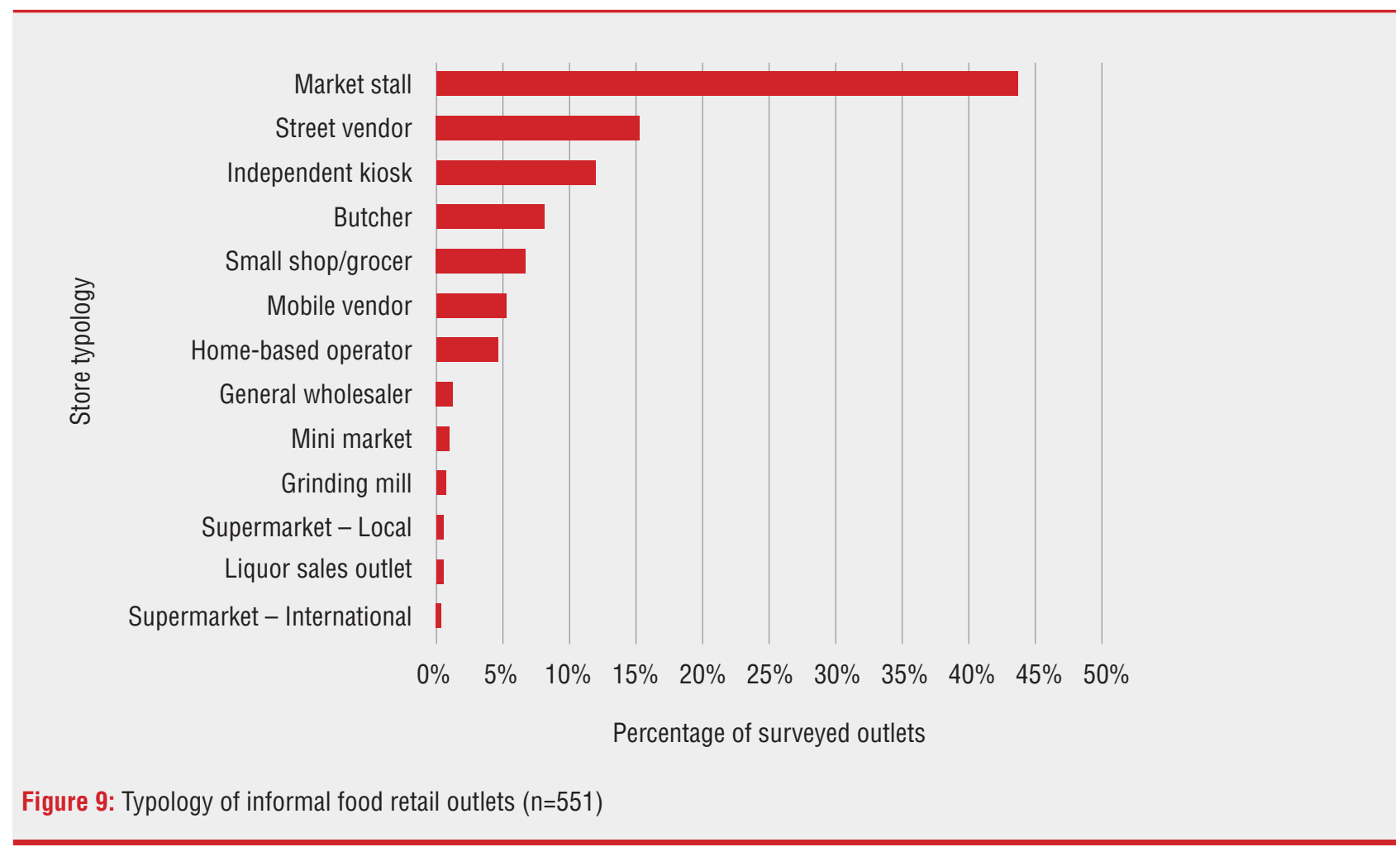

Retailers were also asked to provide their insights on where their patrons originated. Although informed by the retailers' personal views, the responses offer an indication of how traders understand their patrons. Figure 10 reflects the perceived geographic distribution of clients. While informal food retail outlets contribute to promoting spatial access to food in the city, the interviewed traders reported that a greater proportion of their clients (nearly 40\%) come from the retail outlets' immediate neighbourhood. The reported high patronage from within the city is less notable than the relatively high patronage from periurban areas. Peri-urban residents who work in the city buy food in the city on their way home from work. The street vendors, and stand-alone and home-based shops sites outside the city centre, might help residents in terms of time and travelling distance to purchase food. However, the linkage with rural areas might be such that the rural population patronises more of the retail outlets in the main markets during the weekly market days (Sundays), both for household use and retail in the rural communities. These patronage sources add weight to the notion that Kisumu breathes in during the day, absorbing patrons from other areas, and breathes out at night. 


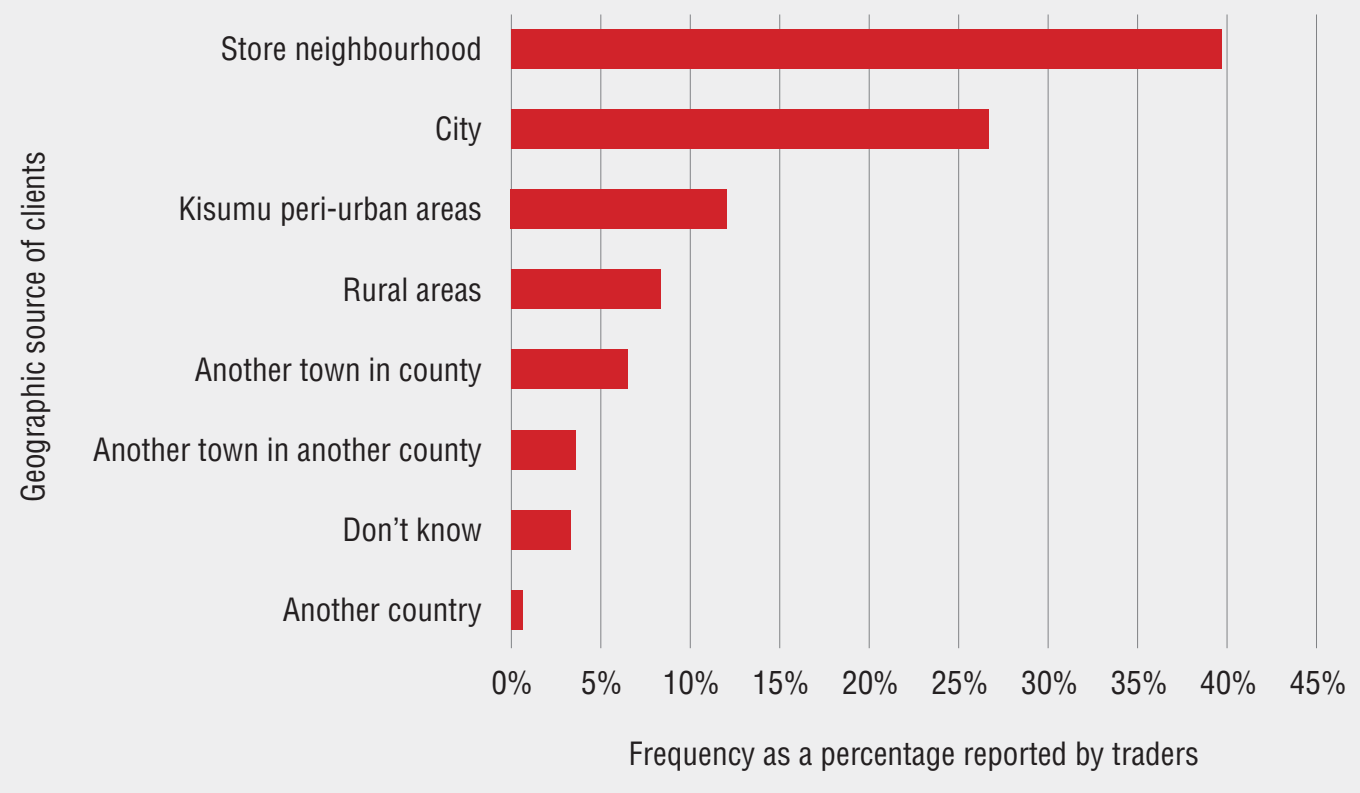

Figure 10: Geographic distribution of informal food retail clients (multiple-response question $n=1043$ )

Generally, the spatial distribution of informal food retail outlets and their typologies seem oriented towards meeting the varied needs of city residents. The role of informal food retail is crucial, given what appears to be relatively low supermarket patronage, particularly by poorer segments of the city. Ensuring balance among the various typologies could serve to promote access to food in the city, especially among the urban poor without ready physical or economic access to motorised transport, who may not have stable income to buy in bulk or have storage facilities for larger purchases when these are affordable. Thus, standalone shops, street vendors and home-based shops may be very important for the urban poor in terms of convenience, proximity, bulk-breaking and extended trading hours. These issues are explored in the next section dealing with the nature of business operations in the informal retail subsector.

Given the dominance of so-called informal-type trading options in Kisumu, particularly market stalls, neighbourhood shops and street vendors, the survey sought to investigate food traders' modes of business. The following section considers the type and nature products (packaged, pre-cooked, etc.) sold by traders, trading practices such as hours of operation and trading days, and specific store operating strategies such as bulk breaking and offering credit.

\subsection{Nature of business operations}

\subsubsection{Product mix}

Kisumu's food retailers trade in varied and diverse products (Figure 11). The main sources of carbohydrate include bread, grains, roots and tubers, sugar, and oils and fats. Protein-rich products include meat (fresh and frozen), fish (fresh, dried and smoked), eggs, chicken and pulses, making it the most diverse category in the product mix. Fruits, dairy and vegetables constitute the main sources of minerals and vitamins. Of all the food products, fruits were reported as the dominant product sold by retailers $(25 \%)$, followed by vegetables $(25 \%)$, sugared drinks (19\%), eggs (19\%), dried grains (16\%) bread (15\%), and snacks, chips and crisps (15\%). The highly-traded food products may be those that meet the daily dietary demands of households (see CUP Working Paper 4: The Characteristics, Extent and Drivers of Urban Food Poverty in Kisumu, Kenya).

In part, the product mix could be influenced by the sampling strategy, given that a predominance of market vendors were included in the survey. However, this potential limitation offers insights into the possible benefits of broader nutritional access, where municipalities play an active role in providing infrastructure that could improve or enable greater access. 


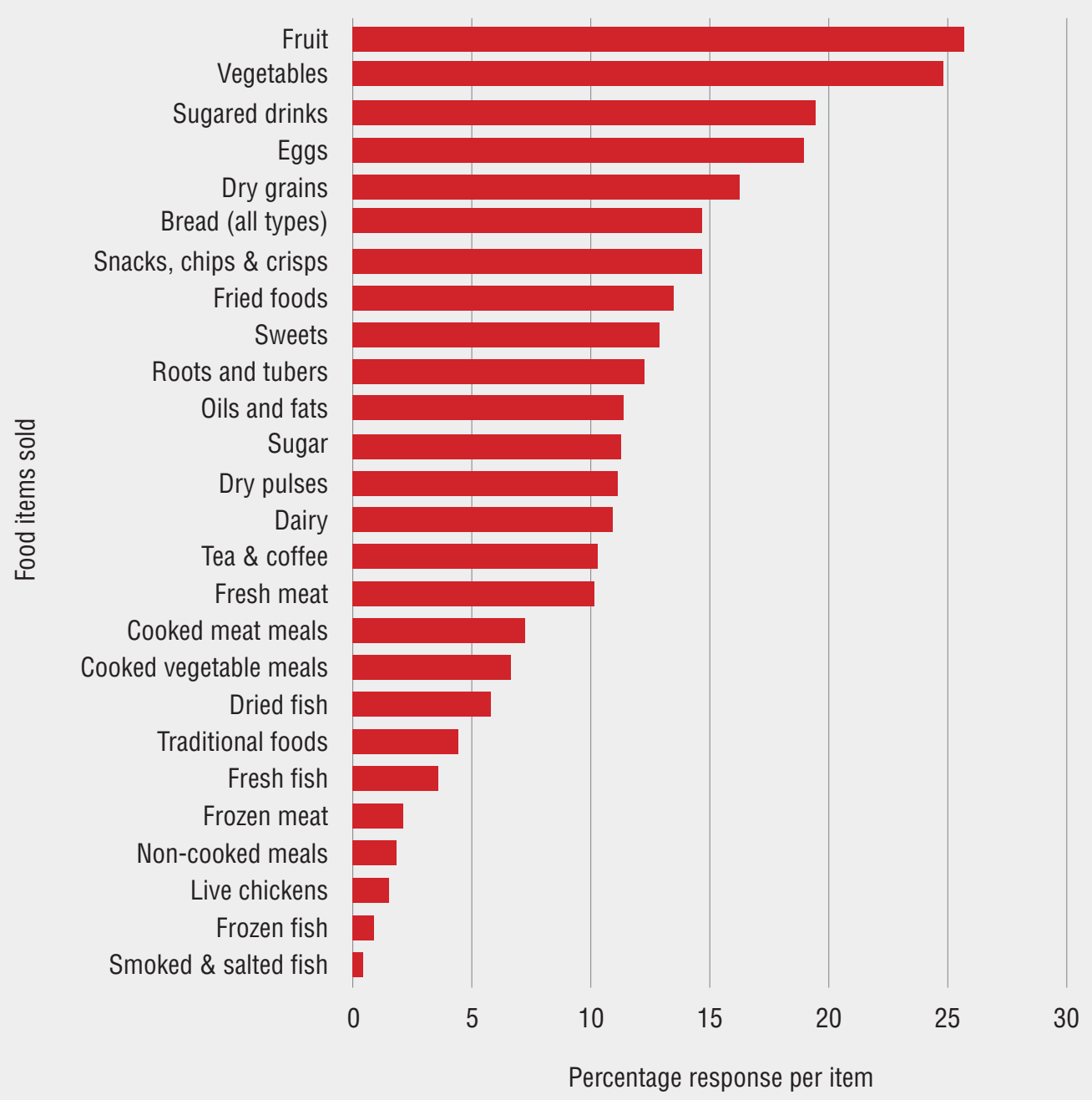

Figure 11: Product mix sold by respondents in Kisumu (multiple-response question $n=1043$ )

It can also be argued that the most traded products are those that are ready to eat, or cheaper and easier to prepare. The least traded products are those that require more energy to cook and/ or preserve. In particular, fruits, sugared drinks, and snacks, chips and crisps fall within what could be termed the 'quick and ready-to-eat' category of foods, which are easy to consume between meals and during the commute to and from work. Ready-made food (cooked and fried) was reported in small numbers (161 cases out of 1501 ), but the quick and ready-toeat bundle, in addition to tea and coffee, accounted for about 547 cases (out of 1 051) of food products traded among the respondent traders that are designed to be consumed 'on the go' or soon after purchase. The low scores for traditional foods, which are indigenous and culturally embedded (dried meat, ghee, indigenous vegetables, etc.), possibly indicates changes in food preferences due to globalisation; urban food provisioning has become increasingly globalised, with attendant diet and nutrition transition (Kennedy, Nantel and Shetty, 2004; Mendez and Popkin, 2004; Steel, 2013; Wiskerke, 2015). It may also be the result of local environmental conditions (climatic and edaphic factors) and agricultural dynamics that affect the availability of the constituents of the traditional foods bundle. ${ }^{2}$ It is perhaps too

2 In this survey foods that may be generalised broadly as traditional to Kisumu (e.g. fish and ugali) were detailed as specific categories and are not part of the reported traditional foods category. This may lead to different levels of reporting when the results are compared to those of other studies. easy to regard the increase in some snack foods, or 'globalised foods', as driven by social and environmental factors. For traders, access to infrastructure and key services also influence the nature and mix of foods and products traded, which will be discussed later in this paper. Theoretically, the mix of food products in Kisumu indicates a balance of carbohydrates, proteins, vitamins and minerals. This suggests that many city residents derive their daily essential energy, protein and micronutrient intake from the informal food retail sector, similar to street foods' significant contribution to the intake of vital nutritional components in some other sub-Saharan African city populations (Steyn, et al., 2013). Further discussion on household food sourcing, consumption patterns and dietary diversity is presented as part of the wider household survey conducted in Kisumu (see CUP Working Paper 4: The Characteristics, Extent and Drivers of Urban Food Poverty in Kisumu, Kenya). Having reviewed the types of food products traded, we now focus attention on the nature of these products. There may be some overlapping terminology - for example, fresh food (general) versus fresh items (fresh fish, meat, etc.) but this classification allows for an appreciation of issues such as modes of handling, preservation, storage and the infrastructural requirements of the various food products.

The reason for this differentiation is that several food items sold within the fish and ugali categories did not have the same traditional sources, such as fish imported from China or imported maize. 


\subsubsection{Nature of products traded}

The broad categories of food products sold are indicated in Figure 12. Fresh food, at 58\%, accounted for a greater proportion of all foods traded by respondents, followed by mixed foods (17\%) and cooked foods (16\%). Mixed foods refers to retail outlets that traded across different food categories (e.g. fresh, smoked and salted, refrigerated). The categorisation of foods as supplier-packaged or self-packaged was an attempt, albeit a simplification, to assess levels of value chain activities in the informal food retail sector.

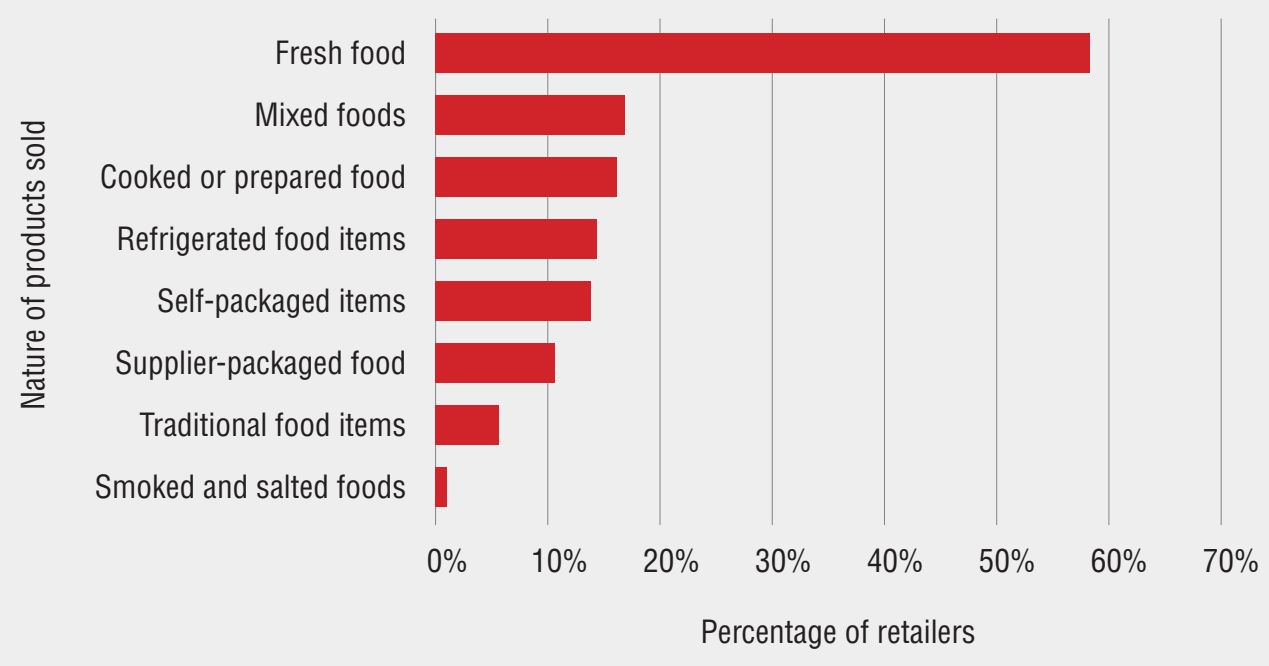

Figure 12: Nature of food products sold by informal food retailers in Kisumu (multiple-response question n=743)

Understanding the nature of food products sold by informal food retailers is crucial to governing urban food systems. However, drawing solely on food products forms only part of the picture needed to inform governance. The next section looks at informal food retail subsector modes of business operation. Issues considered include operating times, operator capacity (labour, infrastructure), relationships with clients (networks), interaction between the formal and informal retail subsectors (networks), and wider food system governance/regulation.

\subsubsection{Informal food retail operating times}

It is often argued that one of the benefits of informal over formal food retail relates to suitable or flexible operating times in terms of hours and days (Skinner and Haysom, 2016). Average working hours among informal food retailers is shown in Figure 13. The greatest portion of respondents (30\%) indicated trading 11-12 hours daily, with those trading 9-10 hours emerging as the second-largest group (21\%). If the number of retailers trading for 9 hours or more per day are combined, it is clear that almost two-thirds (over 64\%) trade on average more than 9 hours per day. This is far longer than most formal operations. The start and close of business is particularly important. As shown in Figure 14 , some informal food retail outlets open for business as early as $05 \mathrm{~h} 00$, with the majority doing so between $05 \mathrm{~h} 00$ and $07 \mathrm{~h} 00$. The majority of respondents indicated that they operated between $18 \mathrm{~h} 30$ and $21 \mathrm{~h} 30$, while a considerable number remained trading until midnight. Compared to the general start and close times of formal retail shops (most likely 07h00-08h00 and 18h00-19h00), the range of informal food retail operating hours enables access to food outside of business hours, when most urban poor have ended work or other livelihood-generating activities (some in the informal but non-food sectors) and are in need of food and other household supplies.

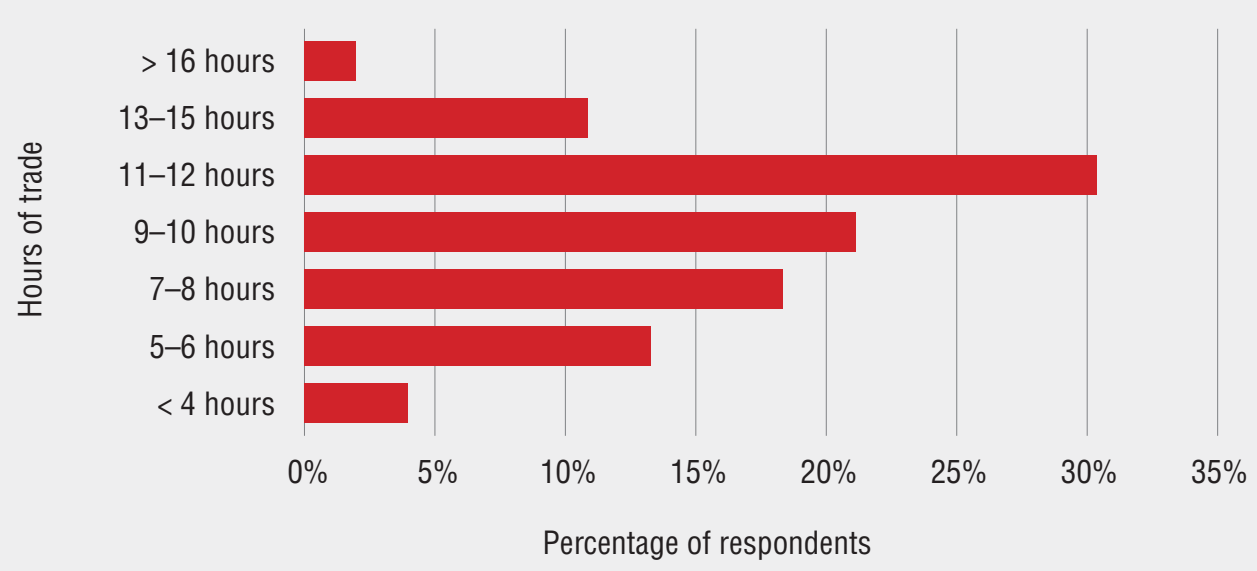

Figure 13: Operating hours of informal food retailers in Kisumu $(n=551)$ 


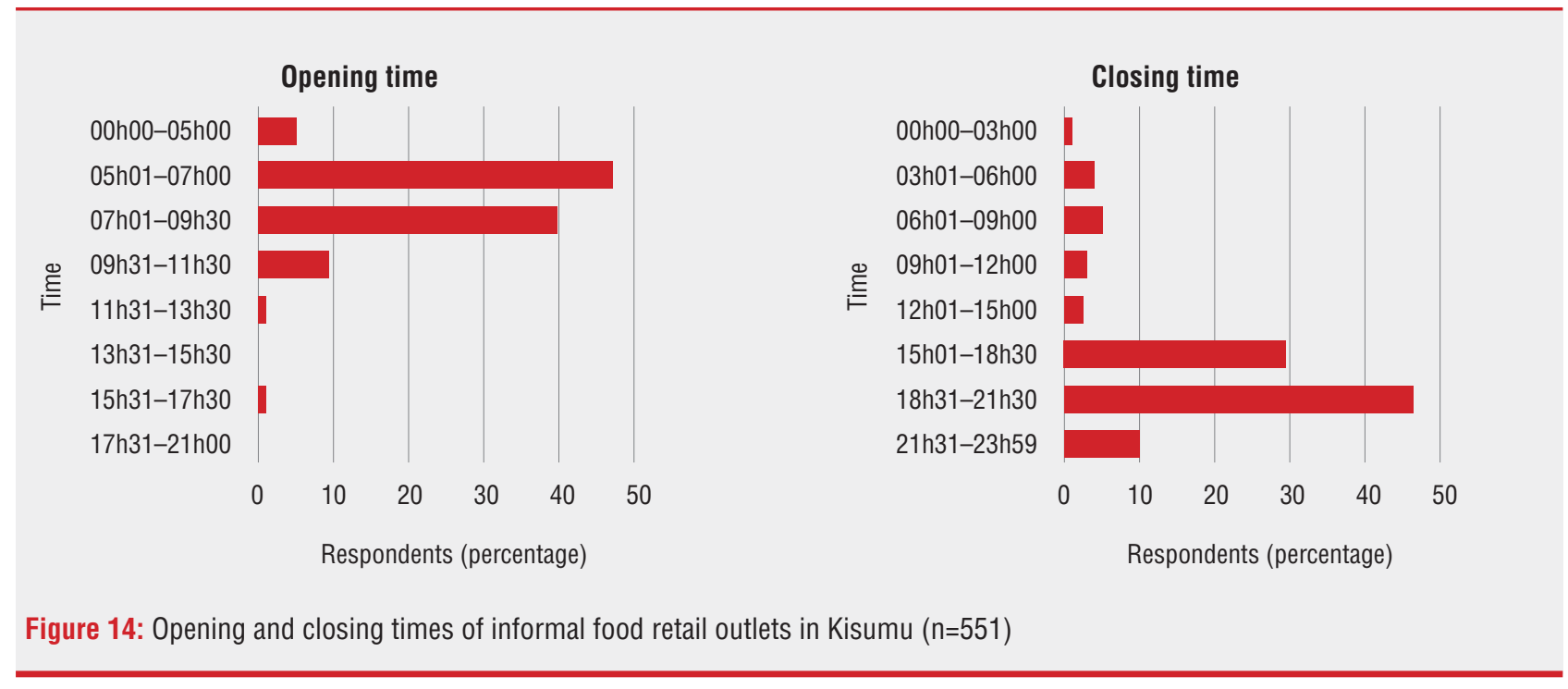

For the survey question that asked retailers to list their trading times in order from busiest to least busy, the majority of respondents ranked morning (08h00-11h30), late afternoon and early evening (16h30-18h30) and afternoon (11h30-14h00) highest, at $49 \%, 47 \%$ and $43 \%$ respectively. These times generally correspond with the times of day when the movement of people is at its greatest, reflecting the earlier finding that passing traffic and commuting to and from work are among the main reasons consumers frequent particular traders. It is likely that the spatial distribution of informal retail outlets experience variations in their busiest trading times, with street edge, stand-alone and home-based outlets benefiting more during the busy hours of the day. The hours of 18h30-21h00 were ranked the fourth busiest trading period by respondents (30\%). This is important because many formal food retail shops begin to close during this time, which means that informal retail outlets that stay open into the night are crucial for filling whatever demand gap remains. The role of the informal food retail sector can also be appreciated in terms of trading days. This also shows how the food system functions irrespective of the formal or informal trade separation discourses. All food outlets are responding to specific needs, economic cycles and foodways of the communities they serve.

\subsubsection{Informal food retail trading days}

In addition to trading times, informal food retail trading days offer insights into the nature of trade and how retail operates within the city. Over $98 \%$ of respondents reported trading Monday to Friday, compared to those trading on Saturday (77\%) and Sunday (63\%). Similar to formal retail shops, some informal food retail outlets do no operate at the weekend, often for religious reasons. Outlets whose primary customer base is made up of workers who only work week days aligned their trade accordingly, with most being closed at the weekend. This was the case for many retailers in Oginga Odinga Road.




The busiest days of trade peak towards the weekend with Sundays reported as the busiest days for many informal food retail outlets. There are several reasons for this: First, Sunday is the main market day for Kibuye market, the largest in the city. Secondly, formal-sector workers have free time to shop on Saturdays and Sundays, so they buy food stock for the weekdays.

The Kisumu survey considered various trader locations and noted 14 general trader typologies. Traders were surveyed in the central business district (often street traders or formal food retail stores), along with market traders at two of the city's busiest markets, and traders in and around one of the largest settlement areas. What emerged from the survey was that informal food retailers apply specific strategies, often different to formal retailers, to either differentiate their businesses, or simply in response to the needs of their customers. In addition to trading hours, strategies included but not limited to bulk breaking, frequent restocking, and building mutually reinforcing relationships to attract and retain customers (e.g. offer credit).

\subsubsection{Bulk breaking}

The strategies of informal food retailers to meet the needs of clients from different social and economic backgrounds are diverse and reflect clients' lived realities. Strategies include bulk breaking - selling products in smaller units, accessible to the poor segment of the urban population - which has also been reported in Cape Town, South Africa (Battersby, 2011). This study attempted to assess whether bulk breaking was a strategy used by informal food retailers in Kisumu. Figure 16 indicates the bulk breaking of selected food products by respondents. There were variations though, regarding the likelihood of bulk breaking specific food products, perhaps based on the nature of the product. Dried grains, dry pulses, fish, meat, sugar, vegetables and fruits were ranked highly as products that retailers would most likely bulk break.

Inquiries in Kisumu revealed that, even though fruits and vegetables are cheaper per unit in supermarkets, poor residents in informal neighbourhoods generally do not buy these items from supermarkets; they would rather purchase from informal traders at the roadside, who sell in smaller units. Bulk breaking is also done for groceries. It is common to find informal traders selling sugar, milk, cooking oil, maize meal, etc. in smaller measures that ordinarily would not be found on supermarket shelves. Small unit measures, locally referred to as the kadogo economy, is a direct response to the needs of low daily income earners. The strategy to bulk break these categories may be mutually beneficial for retailers and their clients. It is likely that these products form the core of an average meal, and selling in small quantities makes it possible for many people to buy them, often on a daily basis. If this argument holds, it effectively creates demand for the food products, thereby boosting sales and possibly increasing profit margins for the retailers.



Figure 16: Bulk breaking of selected food products by informal food retailers in Kisumu ( $n=170)$ 
The bulk breaking of food products by informal retailers may result in higher prices compared to those of formal retail shops. Nevertheless, given the unstable incomes of the urban poor, the spatial distribution of informal retail outlets, and their operating times, bulk breaking is an attractive marketing strategy that is beneficial to both consumers and retailers. The urban poor may be paying more per unit, but bulk breaking enables the division of daily income to meet daily provisioning requirements, meaning that they can buy a small unit of each ingredient for a meal. Sometimes the higher unit prices of bulk broken products are offset by other customer-oriented relationships that are adopted to attract clients. For neighbourhood traders, bulk breaking may offer other business benefits that add value for their customers. Another consideration is additional costs, over and above the item price. When the cost of transport to and from a supermarket or trader market is added to the actual item cost (even if the item is less expensive than the bulk broken item), the bulk broken item cost may be lower than the actual supermarket price. Opportunity costs relating to time, and other aspects such as child care, may make a higher cost for a smaller portion from a local neighbourhood kiosk a more acceptable price for the household.

\subsubsection{Restocking}

Informal food retailers use a range of restocking strategies to maintain product availability and quality. Fresh food products and cooked foods are restocked more frequently, often daily. Products that were infrequently restocked fell within the categories of dry, smoked and salted, which ordinarily do not require significant storage or preservation efforts, and have a longer shelf life.

The logic behind frequent restocking could be that these products are in high demand and items that retailers ought to maintain in regular supply. Another reason is that this practice is linked to the informal nature of trade, sites of trade and services provided to traders. This is a result of limited storage and preservation infrastructure (e.g. refrigeration and the infrastructure to ensure its efficient functioning) that leaves retailers with no option other than frequent restocking. Although the practice may appear cumbersome in terms of cost, frequent restocking offers the advantage of minimising losses through food spoilage, while generally assuring fresher products. Different trader typologies and products would influence the practice of restocking.

The high percentage of traders who engage in bulk breaking (Figure 16), coupled with the frequency of bulk breaking (Figure 17), suggest that, while bulk breaking may be driven in some areas by infrastructure limitations, there are also other reasons. Many informal traders do not have access to adequate capital (discussed later in terms of access to finance), so they tend to stock smaller quantities that are sold on a daily basis before replenishing, using their cash flow to maintain stock levels. This offers insights into the precarious nature of such traders and informal trading as a whole.






\subsubsection{Informal food retailers offer credit to customers}

Another strategy employed by respondents to attract customers is granting credit. This may not appear to be a best-interest strategy for informal businesses, given that their clients are most likely to be the poor, potentially raising the risk of defaulting on repayments. A combined total of $65 \%$ of respondents in this study indicated they give credit as part of their operational strategy (52\% would ordinarily offer credit, while $13 \%$ would do so occasionally). Several motivations were given for offering credit, with the need to retain customers (53\%) and to attract new customers (32\%) cited as the most important considerations (Figure 18). The third most important reason was because other traders do (6.5\%). Credit is used as a strategy to remain competitive in the market. Using economics terminology, the informal retail environment can be described as exhibiting characteristics of perfect competition, which make it difficult not to respond to prevailing market forces. Hypothetically, this makes it possible for consumers to benefit from competitive, but not necessarily low, prices and services.

It is important to highlight the social dimension motivating offers of credit. A considerable number of respondents indicated that to offer credit was both the 'culturally appropriate thing to do' and 'necessary in a poor community'. Some $97 \%$ of respondents who offered credit indicated they did not charge interest. This suggests that informal retail activities might operate as more than just an economic endeavour, and, more importantly, are embedded in the social relations of society. This reinforces, albeit in general terms, the ECA assertion that informal business strategies sometimes go beyond the immediate economic objectives to mitigating other social effects as well (ECA, 2010). Informal food retail may have a greater contribution to make to the food security status of the urban poor than previously imagined.

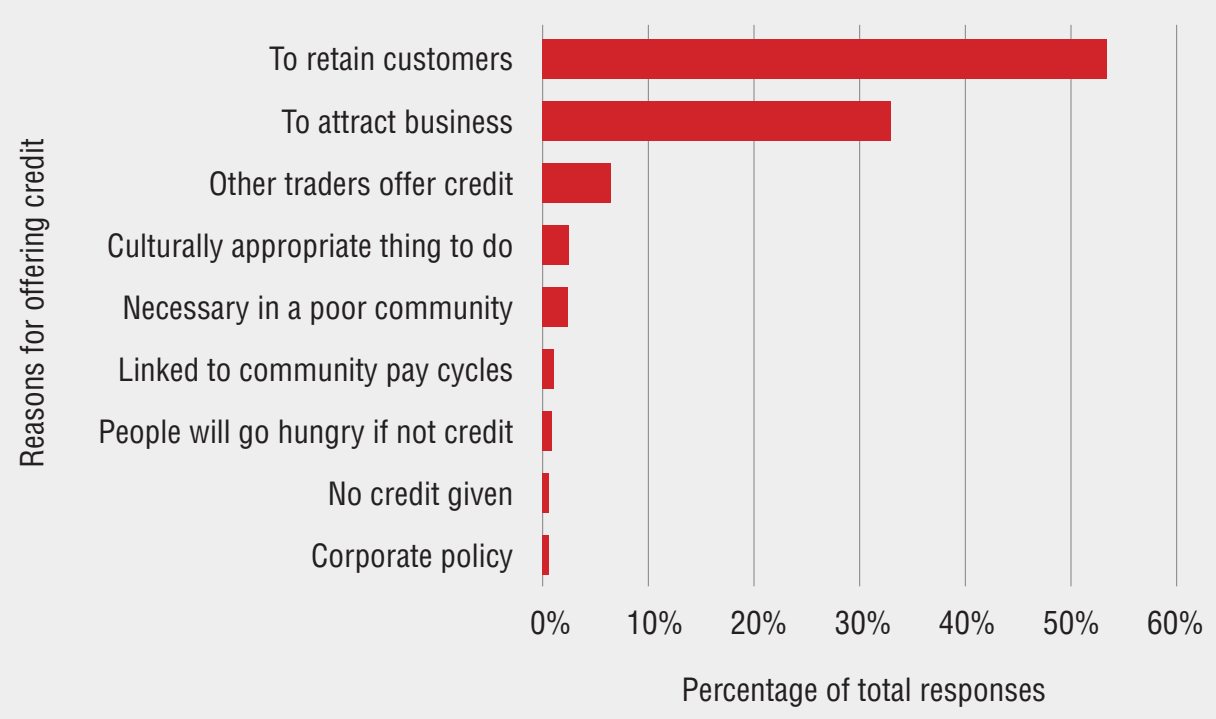

Figure 18: The motivation for informal retailers to offer credit as a business strategy (multiple-response question $\mathrm{n}=892$ )

Retailers were asked who was eligible to benefit from credit. The overwhelming majority ranked regular customers above all others (50\%). However, retailers were also careful about which customers they continued to offer credit, which is reflected in 'clients with good credit' and ranked as the second most important eligibility criterion when advancing credit to clients. 


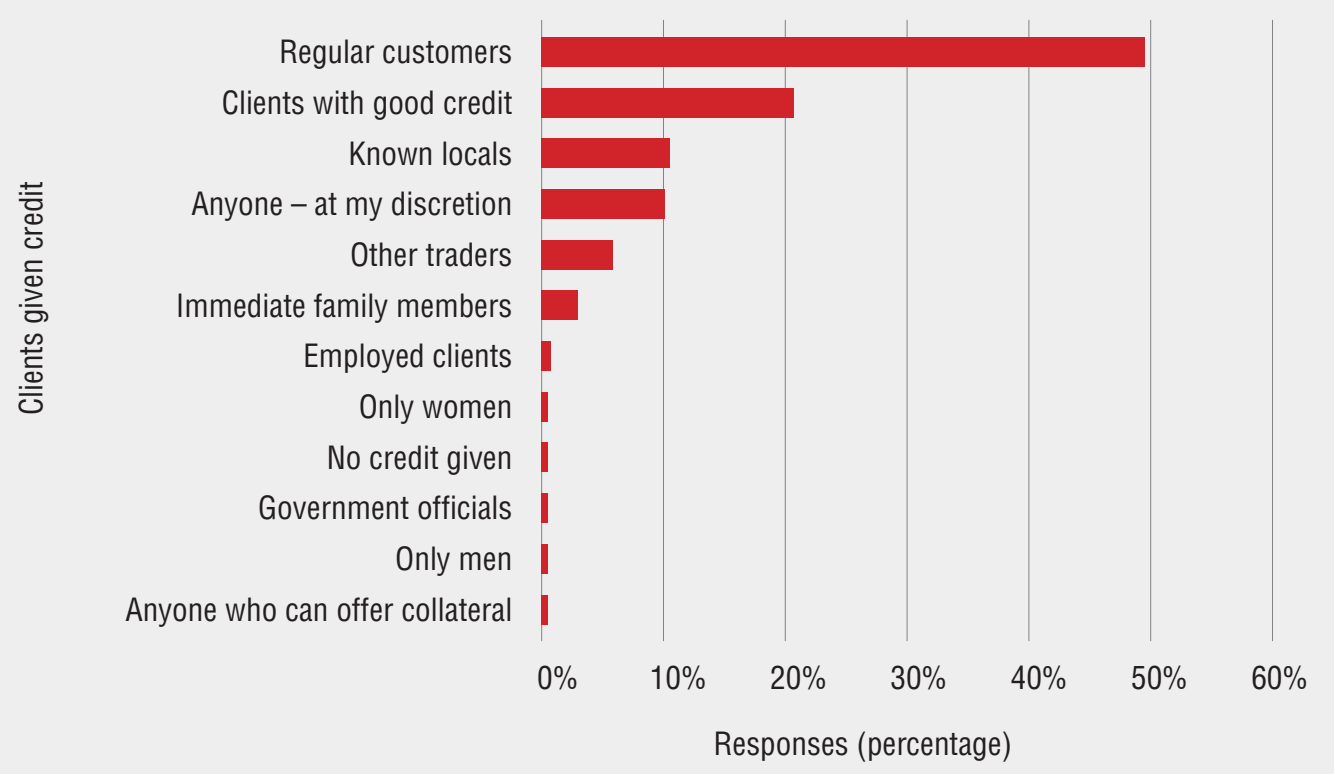

Figure 19: Respondents' views about who qualifies to be offered credit (multiple-response question $n=723$ )

Clients with good credit are those with a history of honouring their debt obligations with informal food retailers. As much as informal retailers seek to attract and maintain customers, and provide social safety nets through credit, there are limits to credit offerings. Traders are also careful about how much of their trade is made up of credit, with over $80 \%$ reporting not having more than $10 \%$ of the volume of their trade in credit sales. Essentially, credit management in the informal retail sector hinges on trust coupled with regular repayments, which explains why dealing with known locals and at one's discretion were ranked relatively high among the retailers' decisions to offer credit. The reliance on trust and honesty in credit management is illustrated by limited calls for collateral (Figure 19). Debt repayment is thus an essential prerequisite should one require credit at a later stage. About $46 \%$ of respondents thought repayment rates were good while, another $45 \%$ rated them as average. Thus, a combined $91 \%$ of respondents considered credit repayment satisfactory. In terms of general credit management successes or losses, over $80 \%$ reported only ever losing $5 \%$ or less of their credit portfolio to bad debt. Some $18 \%$ reported losing $6-10 \%$, and $1 \%$, reported losing higher amounts of $11-25 \%$ of their credit facilities to bad debt. This provides some insight into the operating strategies of retailers, but also the social dynamics at play. While it may be culturally appropriate and ethically important to provide credit, it is also justifiable for a retailer to refuse credit if someone is not actively repaying the amounts owed. This points to the importance of reciprocity within communities and the need to constantly maintain community-scale networks. Traders are engaged in a daily balancing act of maintaining both business viability and community-scale networks.

It is instructive to note that informal retailers also offer credit to fellow traders. This points to a two-pronged business strategy: to attract and retain customers, and to 'insure' themselves against 'rainy days', when they themselves may need support from fellow traders. Credit as a business strategy might involve building both vertical and horizontal networks of relationships to promote the operations of individual retailers. As Roever (2014) notes, most own-account informal traders (who were the dominant respondents in this study) take on all the risk associated with their businesses. Therefore, the strategies employed by informal food retailers constitute a rational hedging against any undesirable situation that might arise out of any unforeseen business failure.

The pro-poor orientation of credit as a business strategy also reflects the low likelihood of employed clients and government officials being offered credit (Figure 19). However, it is unclear whether these categories of clients would seek credit from retailers, and these dynamics could be investigated further in future research.

Another interesting finding is that gender seems to have no real influence on eligibility for credit. For example, a combined percentage of less than $1 \%$ of respondents indicated they would offer credit to men only or women only, even though there were indications that women were twice as likely to be offered credit $(0.6 \%)$ as men $(0.3 \%)$. However, it should be noted that it is women who are primarily involved in sourcing food.

From the data presented above, it is clear that the three business strategies employed by informal food retailers - bulk breaking, frequent restocking and extending credit to clients - have the potential to impact positively on the access and stability dimensions of food security status of the urban poor. These strategies not only make it possible for food to be made available where it is needed, and accessible in appropriate, affordable quantities, but also ensure the development of social relationships beyond the economic realms of business. Therefore, they are central to any discussion of the informal food retail sector's contribution to the food security status of poor urban households.

\subsection{Performance ratings of informal food retail businesses}

Attempts are made in this section to gauge the performance of informal food retail businesses from the traders' perspectives. The section starts with traders' views of the general performance of their businesses. This is followed by discussions on other measures of business performance, including perceptions of profitability, contributions to household income, employment generation, and possible contributions to municipal or local government revenue. 


\subsubsection{General performance ratings}

Respondents were asked to rate the performance of their businesses on the scale of very good, good, marginal, or poor. The majority (51\%) indicated that business performance was marginal, while just under one-third categorised their business's performance as good (32\%) or very good (1.5\%). The remainder reported poor business performance. To get a sense of business performance over time, respondents were asked to compare their current and historical performances, as well as those of other traders. Figure 20 illustrates respondents' perceptions regarding the relative performances of their businesses. Similar proportions reported that business performance was better (34\%) or worse (34\%) than it was the year before, making it difficult to ascertain whether the general retail environment has improved or declined. In terms of comparative historical performance beyond the previous year, however, the majority (40\%) of respondents were of the view that their current performances were better than in the past.

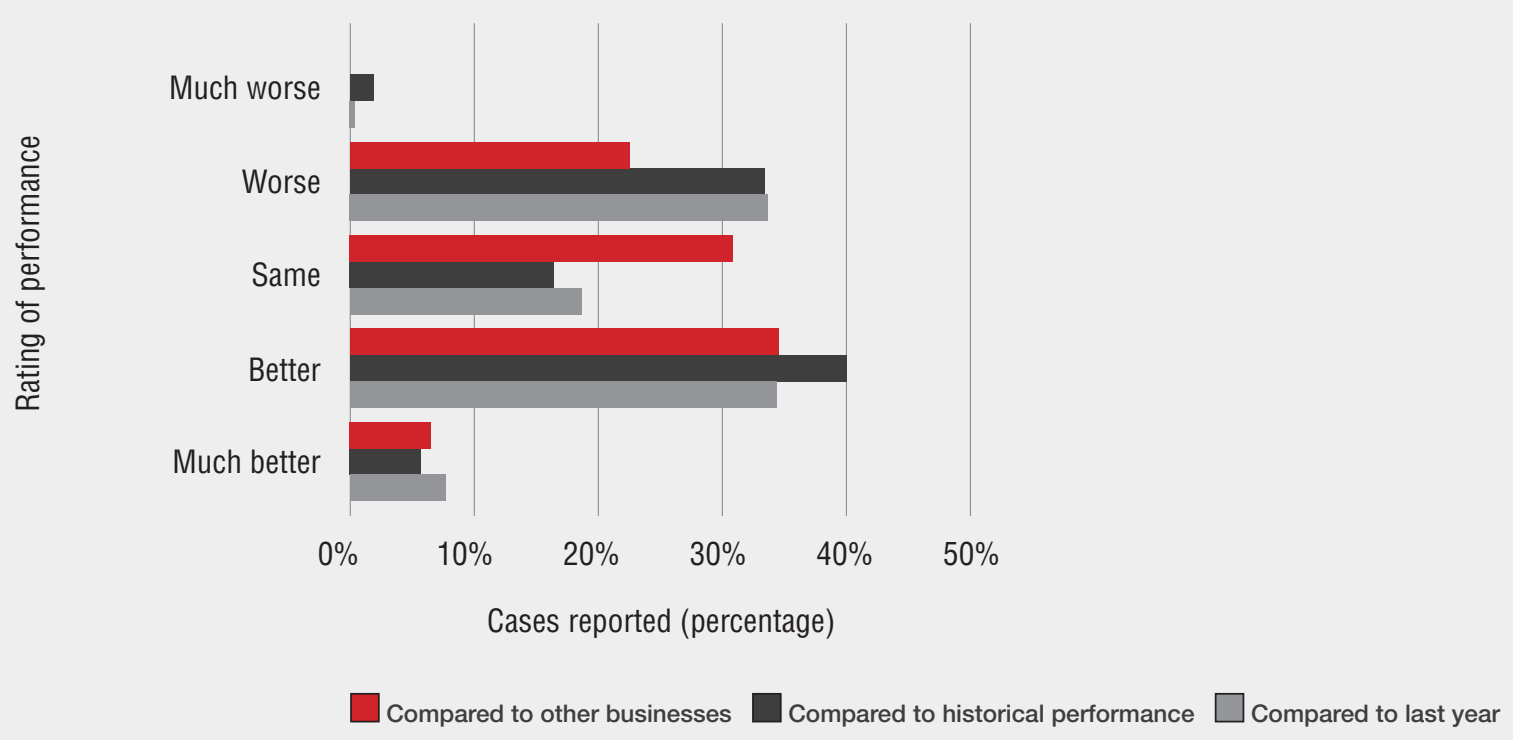

Figure 20: Comparative performance rating of informal food retail businesses $(n-550)$

The majority of traders who reported their businesses performed much worse $(89 \%)$ said that they could not stop trading because it was their only source of livelihood and income. The balance continued to trade in the wake of 'much worse' performances, with the hope that their businesses would improve, some reporting that they 'simply love to trade'.

It might be difficult to appreciate respondents' business performance ratings over time (Figure 20) as these responses need to be read in the context of the period traders have been actively trading. Despite a lack of clarity on the perceived performance of trade, $65 \%$ of traders reported having been involved in trade for three years or more (Figure 3 ). This is because it is likely that some traders do not keep records of their business performance, and rely on memory to relate their experiences. While there is no doubt that memory-based record-keeping can be effective among informal traders, the degree of certainty to which they can recall past experiences may be subject to factors unrelated to the specifics of the business operation, and should be viewed as subjective. As a deliberate research strategy, we simply asked about the traders perceived performance; we did not ask specific questions about financial, profit or other economic interpretations of performance. Exactly how performance was defined was left to the trader. Other surveys of more detailed performance indicators may well generate different results. However, the general perception indicators are seen to have merit given the individual nature of trade. The findings point to the precarious and unstable nature of informal businesses generally, and the informal food retail sector in particular.

\subsubsection{Business profit and contribution to household income}

The concept of profit margin is understood differently depending on the nature of labour, whether family labour, non-family labour, or own labour is used. How much profit is made from an informal food retail business and/or the extent of the contribution made by earnings from the informal food retail trade to household income are other ways of measuring the performance of businesses. The majority (over $60 \%$ ) of respondents reported making 5-20\% profit on total income (Figure 21). A considerable proportion (19\%) was making over $20 \%$ profit. Only about $0.5 \%$ of respondents indicated they were running at a loss. The reported profit margins appear to contradict the general trends of business performance presented earlier vis-à-vis the considerable not-sowell performance rating. However, the apparent contradiction might be explained by the magnitude of profit margins (e.g. a trader who used to make $40 \%$ profit may consider current profit of $15 \%$ as much worse). In other words, having a worse performance does not preclude the possibility of making some profit. The possibility that profits may be exaggerated is unlikely as traders normally understate their profits so that they do not attract competitors; to shield themselves from taxation and fees from municipal and other authorities; and socially, to shield themselves from 'dependants'. 


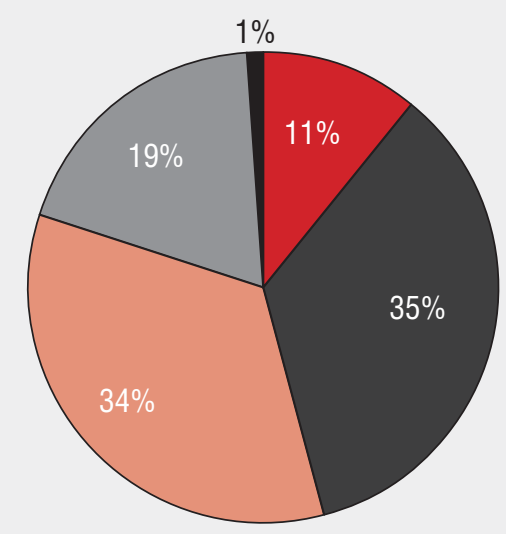

$\square<5 \%$

Between $5 \%$ and $10 \%$

Between $11 \%$ and $20 \%$

$>21 \%$

Run at loss

Figure 21: Respondents' perception of the profitability of their businesses $(n=550)$

Unlike the case of general business performance, the majority of respondents (over 50\%) could not tell if their businesses yielded better profit than those of fellow traders, while about $10 \%$ indicated their profit returns were worse. This may relate to levels of engagement, whereby traders keep actual and detailed business performance strictly confidential. Perhaps one is only able to measure the performance of another's business by sales and frequency of restocking (i.e. the physical manifestation of trade trends) or through observation-based comparisons. However, $30 \%$ thought they made more profit than their fellow traders, suggesting that some level of comparison was possible.

Informal food retail businesses contributed significantly to respondents' monthly household income. Over 16\% of traders reported that income from trading operations comprised more than $75 \%$ of household income. A further $26 \%$ reported that revenues from trade constituted $51-75 \%$ of household income. This combined figure of over $42 \%$ indicates an essential livelihood contribution to retailer households. Only about 20\% of respondents stated that less than $25 \%$ of their household's monthly income came from trading (Figure 22). Over $37 \%$ of traders indicated that trading represented $26-50 \%$ of their household income. This diversity of contributions to household incomes offers insights into the wider economic and employment situation in Kisumu. That just under $57 \%$ of respondent traders generate less than $50 \%$ of their household income from trading suggests diversified household income, despite the high unemployment rate.

The results reflect a broader picture of motivation for engaging in informal food retail; respondents engage in the business for a variety of reasons, including alternative livelihood options and the necessity to provide for families. Any disruptions or poor performance may impact negatively on the ability to meet critical household budget needs.

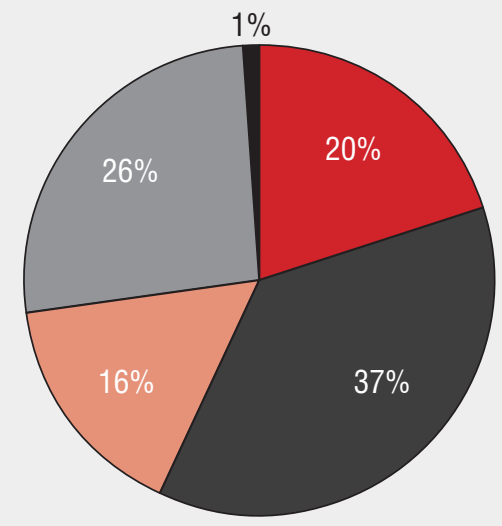

$\square \leq 25 \%$

$26 \%$ tp $50 \%$

$\% 1 \%$ to $75 \%$

$\geq 75 \%$

No household income

Figure 22: Contribution of informal food retail to household monthly income $(n=550)$

\subsubsection{Provision of employment}

As discussed in the section on the characteristics of informal food retail businesses, the sector provides employment to traders and a limited number of employees. Table 2 showed the distribution of employment across self-employed, permanent, casual, seasonal and family members in the mix of staff. It also showed that the greatest beneficiaries of employment in the sector are the selfemployed owners of the outlets, followed by their family members. The low engagement of extra staff may be explained by size and capacity, as most businesses are small and managed exclusively by the owner or with a few family members. However, some owners also employ permanent, casual and seasonal staff. Even though the overall engagement of extra staff is low, it still plays an important role in the urban context, where unemployment is a concern. The informal sector is also associated with the creation of indirect and ancillary jobs in transportation, security, and services such as porterage, all of which contribute to increased economic activity and the performance of city economies (Roever, 2014). Whereas this survey focused specifically on traders, there is a strong likelihood that ancillary jobs have been created, and practices such as frequent restocking may add to the level of employment. Therefore, an assessment of the employment potential of informal retail businesses has to take a broad conception to consider opportunities created for owners and employees, and linkages with other sectors such as transportation, waste picking and service provision. In other words, governing urban food systems through the informal food retail sector has to go beyond ensuring that food is accessible to the various segments of the urban population, and include analysis of the broader linkages with the urban economy. 


\subsubsection{Payment of taxes and rates by informal food retailers}

The last item concerning the performance of informal food retail businesses is the payment of various taxes and rates to local governments. An assumption has been that informal traders do not pay tax to the municipal government because their businesses are often not registered and, by extension, not regulated. Some previous scholars have defined the informal sector as one occurring outside the formal fiscal and labour regulatory frameworks (see, for example, Amis, 2004). Some have also argued that traders engage in the informal sector specifically to avoid paying taxes (De Soto, 1989; 2000). The thinking might be that it is only through formal registration that business entities are required to pay tax, but this assumption is increasingly being challenged with empirical evidence (see, for example, Roever, 2014). This study sought to interrogate the question of tax avoidance by informal business operatives. Figure 23 illustrates the forms of tax informal food retailers reported paying in Kisumu.



Case reported percentage

Figure 23: Forms of tax paid by informal food retailers (multiple-response question $n=580$ )

As indicated in Figure 23, informal food retailers in Kisumu contribute to municipal and national revenues by paying various forms of tax. An overwhelming majority of $88 \%$ reported paying value-added tax (VAT). This was followed by rates or city tax, with a recorded $15 \%$ prevalence. Income tax and employment tax payments were relatively low for the possible reasons that incomes of informal traders are difficult to track and levy, and the low employment of extra staff means that there are limited opportunities for collecting employment tax. Informal food retailers also contribute to municipal revenue through licensing fees, with about $57 \%$ of respondents indicating that they have a business operating license, for which they had to pay between KES1 000 (USD10) and KES10 000 (USD100), while another $17 \%$ paid vending fees. ${ }^{3}$ Of those with business operating licences, about $94 \%$ obtained their licences from the municipality. These included long-term business operating licences, daily licences and operating permits (e.g. a health permit to sell food). However small these payments might be, they contribute to municipal revenue, which means that the viability or otherwise of informal food retail businesses might impact municipal and national governments' revenues.

In Kisumu, the revenues generated from markets and through trader levies is not insignificant, although market fees collected by the city have declined in recent years. Whether this is as a result of poor collection practices, a reduction in the number of traders, or trader resistance to paying fees is unknown; this is an area for further research. Table 4 details revenues over the 2014-2017 financial reporting period.

Table 4: Kisumu city revenues collected in KES over the financial period 2014 to 2017

\begin{tabular}{|c|c|c|c|c|c|c|}
\hline Revenue streams & \multicolumn{2}{|c|}{$2014 / 15$} & \multicolumn{2}{|c|}{$2015 / 16$} & \multicolumn{2}{|c|}{$2016 / 17$} \\
\hline Land rates (property tax) & 120002382 & $20.9 \%$ & 129635191 & $21.4 \%$ & 138194757 & $22.9 \%$ \\
\hline Single business permits & 84382849 & $14.7 \%$ & 88748755 & $14.6 \%$ & 81022720 & $13.4 \%$ \\
\hline Rent (for government housing) & 30181713 & $5.3 \%$ & 35604969 & $5.9 \%$ & 40955012 & $6.8 \%$ \\
\hline Matatu Bus Park fees & 78489050 & $13.7 \%$ & 84756350 & $14.0 \%$ & 76284500 & $12.6 \%$ \\
\hline Market fees & 63856275 & $11.1 \%$ & 61723245 & $10.2 \%$ & 52459370 & $8.7 \%$ \\
\hline Building plan approval & 19077867 & $3.3 \%$ & 17897651 & $3.0 \%$ & 42630357 & $7.1 \%$ \\
\hline Signboard promotion & 55683113 & $9.7 \%$ & 56610761 & $9.3 \%$ & 59986988 & $9.9 \%$ \\
\hline Sundry revenue & 42837886 & $7.5 \%$ & 47632441 & $7.9 \%$ & 12376746 & $2.1 \%$ \\
\hline Public health & 3049000 & $0.5 \%$ & 2427644 & $0.4 \%$ & 9501800 & $1.6 \%$ \\
\hline Parking fees & 75839331 & $13.2 \%$ & 81305291 & $13.4 \%$ & 89815950 & $14.9 \%$ \\
\hline Total & 573399466 & & 606342298 & & 603228200 & \\
\hline
\end{tabular}

(Source: Cirolia publication pending)

Exchange rates as of 26 January 2017 
However, as Roever (2014) notes, the contribution of informal traders to revenue generation goes beyond the local level to national government level through the payment of VAT. In this regard, the overwhelming majority of respondents who pay VAT certainly contribute to national government revenue.

The often-precarious nature of informal trade, particularly for those operating outside the designated (and controlled) municipal markets, means that the likelihood of exposure to other forms of rent extraction increases. Traders are often forced to pay other forms of 'tax' that fall outside any official recording or collection of tax. The nature and form of these 'taxes' are often informed by the nature and transparency of governance structures in place to regulate food retail in the city.

\subsection{Governance and regulation}

This section presents the governance and regulatory regime of informal food retail in the study area, including permitting and inspections. These are two common tools used by municipal governments to regulate informal economic activities. The interaction of informal businesses with formal governance structures often happens through licensing, and enforcement of same through periodic or regular inspections to ensure compliance. For this reason, governance and regulation represents a point of interaction with the informal economy that is full of tensions and contestations, as regulation can easily jeopardise the existence and viability of the very informal businesses meant to be regulated (Amis, 2004). In other words, the character of the informal retail sector is shaped largely by processes of governance and regulation, often making the legitimacy of these businesses and their operating environments uncertain.

\subsubsection{Permitting and licensing}

Permitting and licensing are common tools employed by municipal authorities to manage or control informal retail businesses, including food retail. It serves two basic purposes: granting legitimacy to informal businesses and regulating product quality and public health issues. Three-quarters of respondents in this study reported possessing some form of operating licence, including those who had applied and were still waiting for their permits/licences. The remainder comprised 6\% who thought their businesses did not require an operating licence, and about $19 \%$ who traded without licence. Figure 24 shows the different types of operating licence available to respondents in the study.

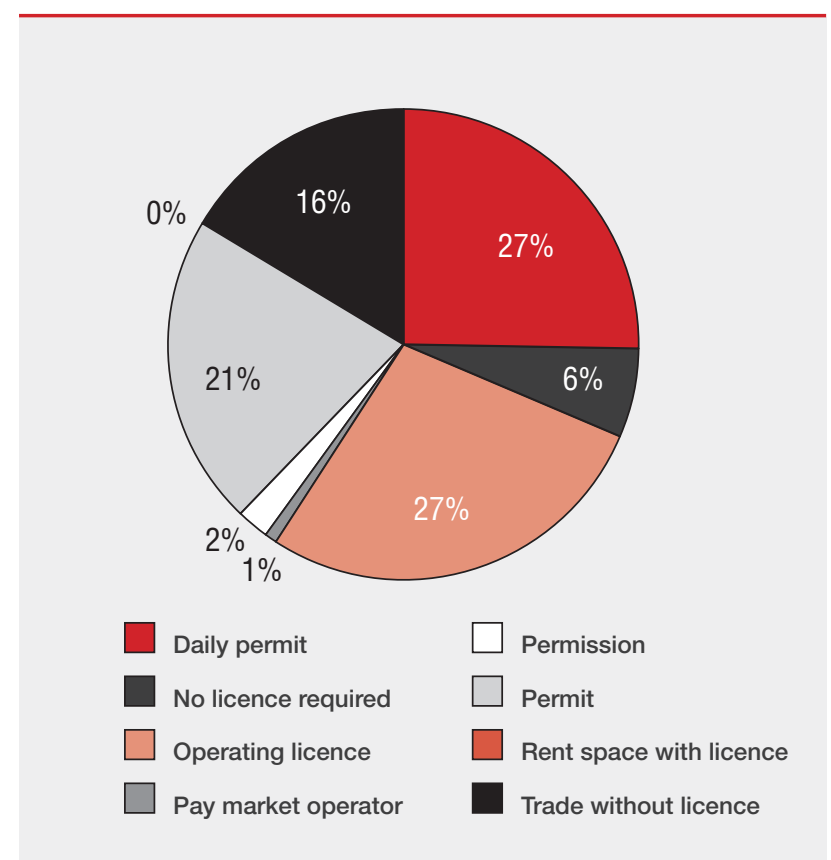

Figure 24: Different licensing forms held by traders (or absence thereof) $(n=547)$

An operating licence, daily permit and permit were the most common forms of authorisation that legitimised the activities of respondents. An operating licence is the formal annual authorisation that allows a trader to operate in a permanent/ fixed place, whereas a daily permit is authorisation to trade in a given space on a daily basis. Some informal food retailers also obtained permission to trade in complementary products alongside established outlets, in a symbiotic relationship, where the established outlets' customers patronise the products of 'squatting' outlets and vice versa (e.g. a grilled/roasted meat stand near a butchery). A permit is the authority to deal in a particular item (e.g. food handler's permit). The different types of permits apply to different typologies of trader. Whereas Figure 24 provides an overall sense of the permitting arrangements across Kisumu, Figure 25 provides greater nuance, indicating as a proportion of each type of trader the different licencing types and approaches to licencing. Figure 25 highlights the importance of avoiding broad generalisations about traders and food retailers, specifically informal retailers. It is important to note that, given the small sample size, these figures are not statistically significant. 


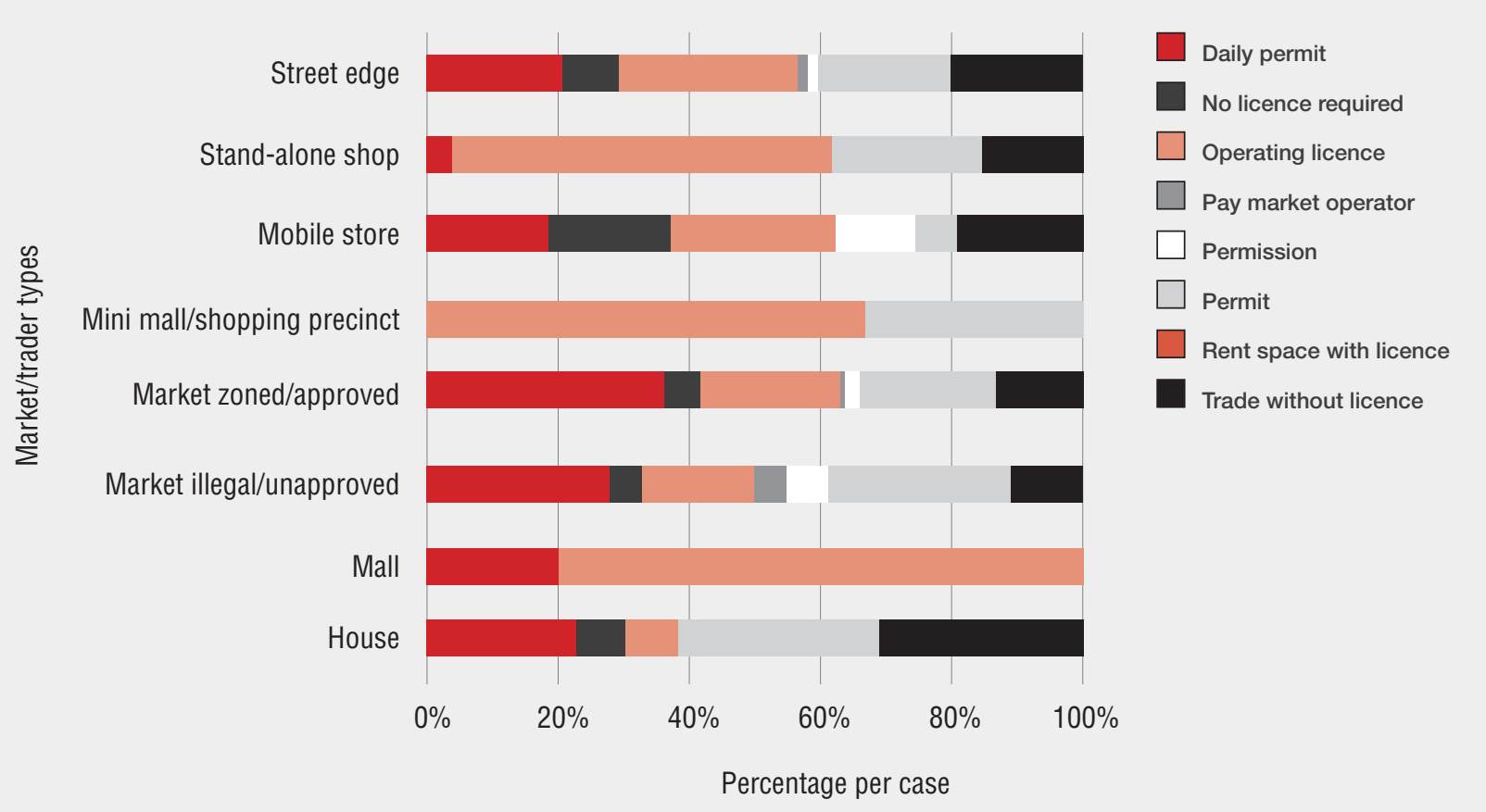

Figure 25: Licencing and permitting per trader typology $(n=547)$

House shops, mobile vendors and some street-edge traders report high levels of 'trading without a licence', while mall operators and mini malls/shopping precincts reflect how annual operating permits dominate. What is perhaps more interesting are the traders who operate in formally designated market areas without a licence. The fact that illegal or unapproved market traders, although a small percentage of the total trader sample, still pay regular permit and licencing fees raises urban food governance questions.

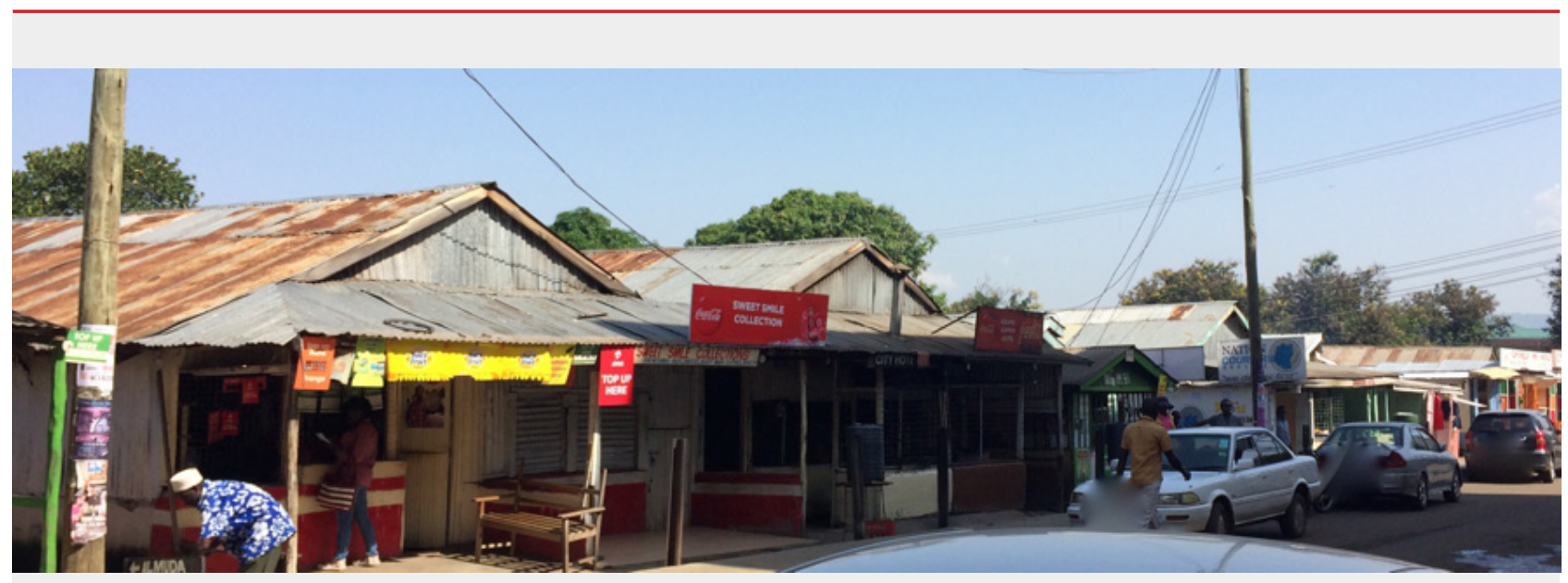

Figure 26: Dining establishments in old railway structures along Bank Street, Kisumu (Photo: Gareth Haysom)

Given the sampling strategy applied in this survey (samples from formalised market spaces and other neighbourhood trading spaces), the findings on permitting still contrast with what could be described as common reasoning that informal traders often ply their activities 'illegally' in urban spaces. Informal traders are not necessarily illegal in the Kisumu context. Formality or informality of food retail in Kisumu is defined by the type of trading premises (permanent or temporary); location of the business (in approved market/shopping centre, or unapproved market/roadside); and legal status of the business enterprise (registered/licensed or unregistered/unlicensed).
Food traders often described as 'illegal traders' in municipal and even formal food system discourses, such as roadside food vendors, 'legitimise' their activities by paying daily permit fees to municipal authorities. If the case of street-edge traders is considered, over 70\% of traders reported having some form of official permit or licence, raising questions about the use of the term illegal and the notion that these traders are explicitly trying to avoid paying taxes and levies. In Kisumu, the majority of respondents not only had authorisation to trade in the spaces they did, but also obtained such authorisation from the municipal authorities and a selection of other sources. 
About $94 \%$ of the respondents who had authorisation to trade indicated that they had obtained it from the municipal authorities, with another $4 \%$ getting authorisation from market operators. The remaining respondents (2\%) obtained their authorisation to trade from local custodian, store owner, business chamber and national licencing sources. This reveals the hierarchies and complexities of governance issues relating to the entitlement and use of urban space, of which formal urban governance structures and processes must take cognisance.

It is worth noting that questions about trading with a licence were followed up with a sub-question, where traders were asked: 'If you were asked to produce the physical permit/licence, would you be able to do so?' Here, again, the positive responses aligned with reported permitting.

The high incidence of respondents trading with a licence or permit suggests that the processes of regulating informal food retail businesses through licencing and permitting are flexible and acceptable to many traders, contrary to the cumbersome processes that are often associated with licencing informal business activities elsewhere (King, 2006; Setšabi, 2006; Kamete, 2012). This reflects the favourable rating for ease of securing a business operating licence by the majority of respondents (Figure 27). Over $50 \%$ of respondents who traded with some form of licence or permit thought it was easy to acquire a business operating licence. Another 30\% thought the process was associated with some delays, and only $1 \%$ rated the process as very difficult. Affordable cost might have contributed to the favourable rating of licencing processes. As shown in Figure 28, slightly over half of the respondents indicated paying between zero and KES1 000 (USD10) to secure their business operating licences, with another 36\% paying between KES1 001 and KES5 000 (USD10 and USD50).

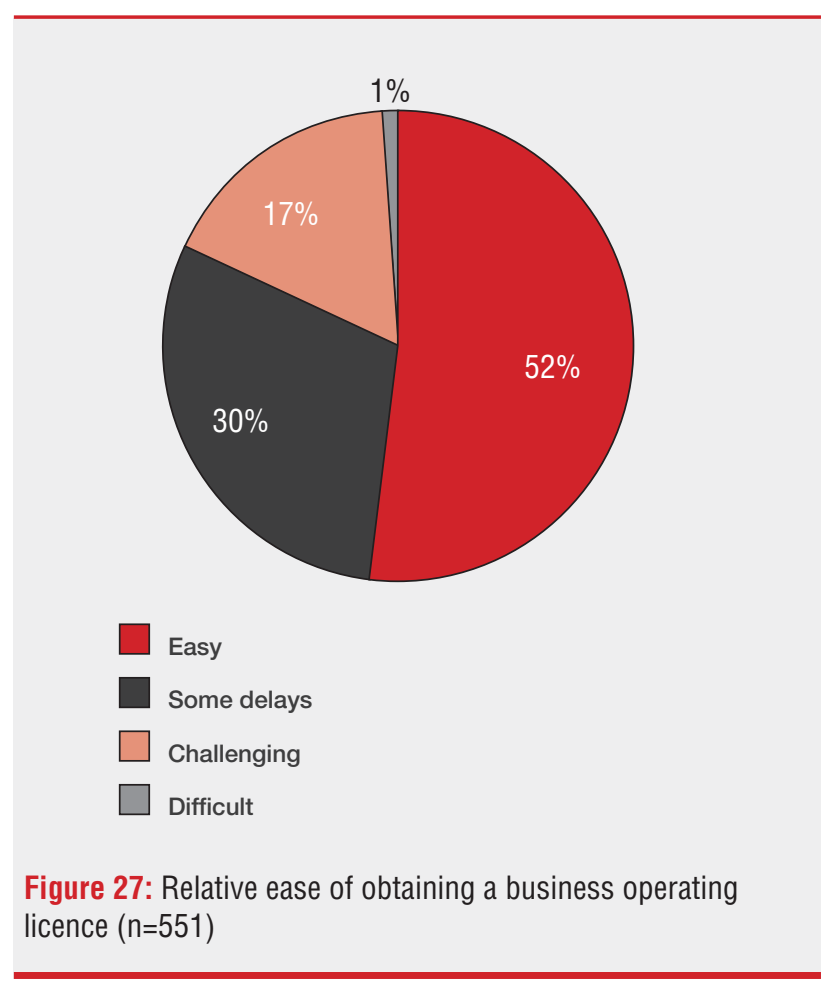
between informal businesses and formal governmental agencies. In the absence of sound and known inspection-related governance processes, inspections can provide avenues for unscrupulous inspecting agents to harass and extort monies from informal traders. Apart from asking questions about the bodies responsible for inspections, questions were posed to understand the nature of inspections in the study area. These related to respondents' perceptions of whether inspections were done according to the law, and if there were ways respondents could avoid being inspected. On whether inspections were done according to the law, $46 \%$ of the respondents said 'yes', while $21 \%$ indicated 'sometimes yes, sometimes no. Those unsure about their responses constituted $14 \%$ of the 'maybe' responses. Only $3 \%$ of respondents were categorical that inspections were not done according to the law. What is certain is that more than half of the respondents could not categorically characterise the inspection processes as being executed within the 
framework of the law. This raises questions about the governance of traders and their relationship with officials.

Concerning the possibility of avoiding inspections, $44 \%$ of respondents indicated that there was no way to avoid being inspected, while the rest thought there were ways of doing so. Those who thought inspections were avoidable mentioned several strategies including pay bribes (19\%), ceasing trading until inspectors move on (15\%), being mobile in their operations (8\%), paying protection money ( $8 \%$ ), holding small stock quantities (4\%), and paying market operators $(2 \%) .{ }^{4}$ The relatively high incidence of bribe payment as a strategy to avoid inspections raises questions about the relationship officials have with traders. Although bribery is a form of extortion, it often guarantees some informal traders space to trade in the sense of Benjamin and Bhuvaneswari's (2001) concept of 'politics of stealth', in which poor and vulnerable groups engage with politicians, officials and other powerful institutional actors to push certain agendas and secure their own interests, contrary to rules and law. According to Amis (2004: p. 158), it is through 'politics of stealth' that the poor and their alliances engage and negotiate with local-level officials to solve problems in unofficial and non-transparent ways, outside the permissible system. Thus, the relationship between certain traders and officials may not necessarily be detrimental to informal businesses. What is of interest is the fact that bribes and other forms of 'politics of stealth' are active in an environment with highly overt and deliberate licencing processes, particularly given the high levels of permit holding that was reported (Figure 24).

\subsection{Food retail challenges in the study area}

This section presents some insights into the challenges that confront informal food retail businesses in their operating environments. Although there have been some inherent challenges mentioned in passing in this paper (e.g. loss of income to bad debt, issues with governance and regulatory processes), more fundamental challenges prevalent in the informal food retail sector operating environment need to be considered. Thus, three main challenges are discussed in this section: access to appropriate infrastructure and services, access to financial support and operating costs, and specific threats to the sustainability or viability of informal food retail businesses.

\subsubsection{Access to appropriate infrastructure and services}

By its nature, the informal food retail sector requires certain critical infrastructure and services to enhance its viability and facilitate the provision of quality and wholesome products. Fresh food and cooked food products, for example, need water and appropriate storage infrastructure to prolong product shelf life while maintaining acceptable quality standards. Figure 29 indicates the categories of infrastructure and services available to informal food retailers in the study area. As shown in the figure, the most accessible facility for food retailers was 'shade. This is understandable in the sense that 'shade' could mean anything that provided protection against direct sunlight, or rain, and could be constructed. However, access to other physical infrastructure that provided better protection was relatively low, as seen in the responses on access to formal trading space, paved floor surface, rain-proof structures, secured storage, and refrigeration. In terms of access to services, a relatively high proportion of respondents reported having access to electricity compared to sanitation (less than 50\%), waste disposal facilities (less than 60\%), and piped running water (less than 70\%). Low access to air-conditioning, designated parking, and electronic point-of-sale facilities reflects the informal nature of these businesses, low car ownership among traders and their patrons which creates a reliance on public transport, and the general unfavourable environments in which they operate.



Figure 29: Infrastructure and services available to informal food retailers (multiple-response question $\mathrm{n}=2358$ )

4 These payments were a form of bribe paid outside of official permit and

licensing payments. 
Figure 29 points to real infrastructure and services challenges faced in the informal food retail sector. As observed in the nature of food products, and retailers' trading and restocking strategies, access to infrastructure and services is crucial to the viability of the sector in terms of appropriate storage of food products and supplying quality products. As indicated earlier in this paper, a disproportionate majority of informal food retailers trade in fresh foods, with a significant proportion also dealing in cooked food. Both of these food product categories require specialised infrastructure, including refrigeration, and a supply of potable and safe water for cleaning. Low access to these services impacts negatively on the traders and the consuming public.

Where traders try to adapt to the situation through frequent restocking, they become exposed to another 'operating risk': high transport costs. Loss of stock through spoilage and the high cost of transportation have the combined effect of increasing retailer operating costs, thereby reducing business profitability. These costs are often passed on to poor consumers, impacting food price and food access. The cost of transportation is one of the main challenges that threaten the sustainability and viability of informal food retail businesses. There is also the likelihood that low access to physical infrastructure makes traders susceptible to issues such as theft. Inadequate supplies of clean water and sanitary facilities affect food safety, which in turn exposes the consuming public to disease pathogens and other public health concerns.

\subsubsection{Access to financial support and operating costs}

The study findings show that informal food retail businesses depend largely on self-financing and family income sources for survival. When asked about the sources of funding for their businesses, over $80 \%$ of respondents reported 'own income' as the main source (Figure 30). The second most important source of financial support came from returns from savings club contributions (24\%), where informal traders make regular contributions geared towards capital formation to support both personal and business financial needs. Family loans ranked third at $13 \%$, while cash inflows from own (other) businesses ranked fourth at $12 \%$. The percentage of retailers who sought financial support from banks was relatively high at $9 \%$, compared to microfinance institutions at $2 \%$. This is interesting, given that microfinance establishments often target informal sector operators to fill the gap created by their non-existent status in the formal banking sector. Due to competition, however, banks now increasingly target the informal sector and have developed products similar to those offered by micro-financiers. There are currently more banks in Kisumu engaging in micro finance than the traditional micro-finance institutions, and they have a bigger capital base. While the mutually beneficial relationship between the formal and so-called informal sectors have been well documented, the formalisation of links between formal finance institutions and informal traders is a new finding, and one that opens up areas for significant future research. Given the constrained industrial and economic environments in many African cities, combined with a general disregard of the informal sector, these new networks are of particular interest, if not somewhat expected.

When asked to rate their ability to get financial support, the responses given reflected the financial sources reported above. Over $60 \%$ of respondents reported they never received any financial support for their businesses, while $8 \%$ indicated that no financial support was available to them. Thus, a combined proportion of almost $70 \%$ of all respondents did not benefit from any financial support. Of the remaining $30 \%$, about $10 \%$ could get limited support, while $6 \%$ and $5 \%$ rated their ability to get financial support as average and good respectively. Another 5\% indicated they received support, but that the terms were bad. Reliance on community networks and 'who you know' had a limited impact on people's ability to access financial support. Similar to the case of granting credit reported earlier in this paper, gender was not a deciding factor in respondents' ability to access financial support.

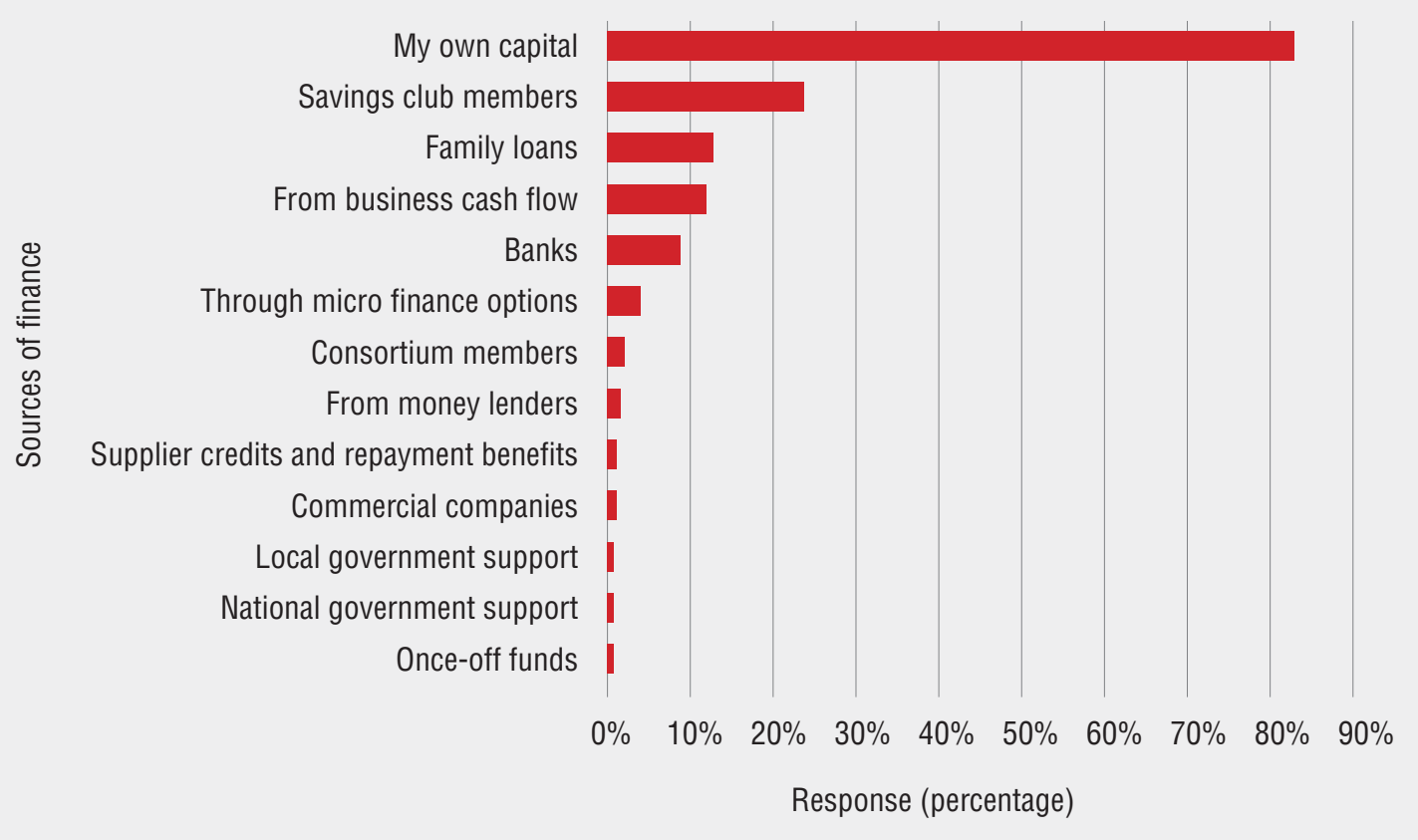

Figure 30: Sources of financial support available to informal food retailers (multiple-response question $n=830$ ) 
An investigation into retailers' operating costs, other than the cost of stock, offers a deeper appreciation of the challenging operating environment. Two aspects stand out: transport and infrastructure. Both factors are informed by the operational challenges described earlier, and these limitations impact informal food retailers. Figure 31 shows the distribution of retailers' operating costs, other than the cost of stock.

More than $80 \%$ of respondents ranked the cost of transportation as the greatest share of their operating cost after stock costs. This reinforces the findings of the five-item food value chain survey that most food is transported to Kisumu from distant areas, often via roads that are in poor state. The survey established that most food items are brought into Kisumu from other counties in Kenya (mostly over $100 \mathrm{~km}$ away), and even imported across the border. Apart from out-of-town transport costs, local transport costs associated with frequent restocking add to the overall transport cost element.

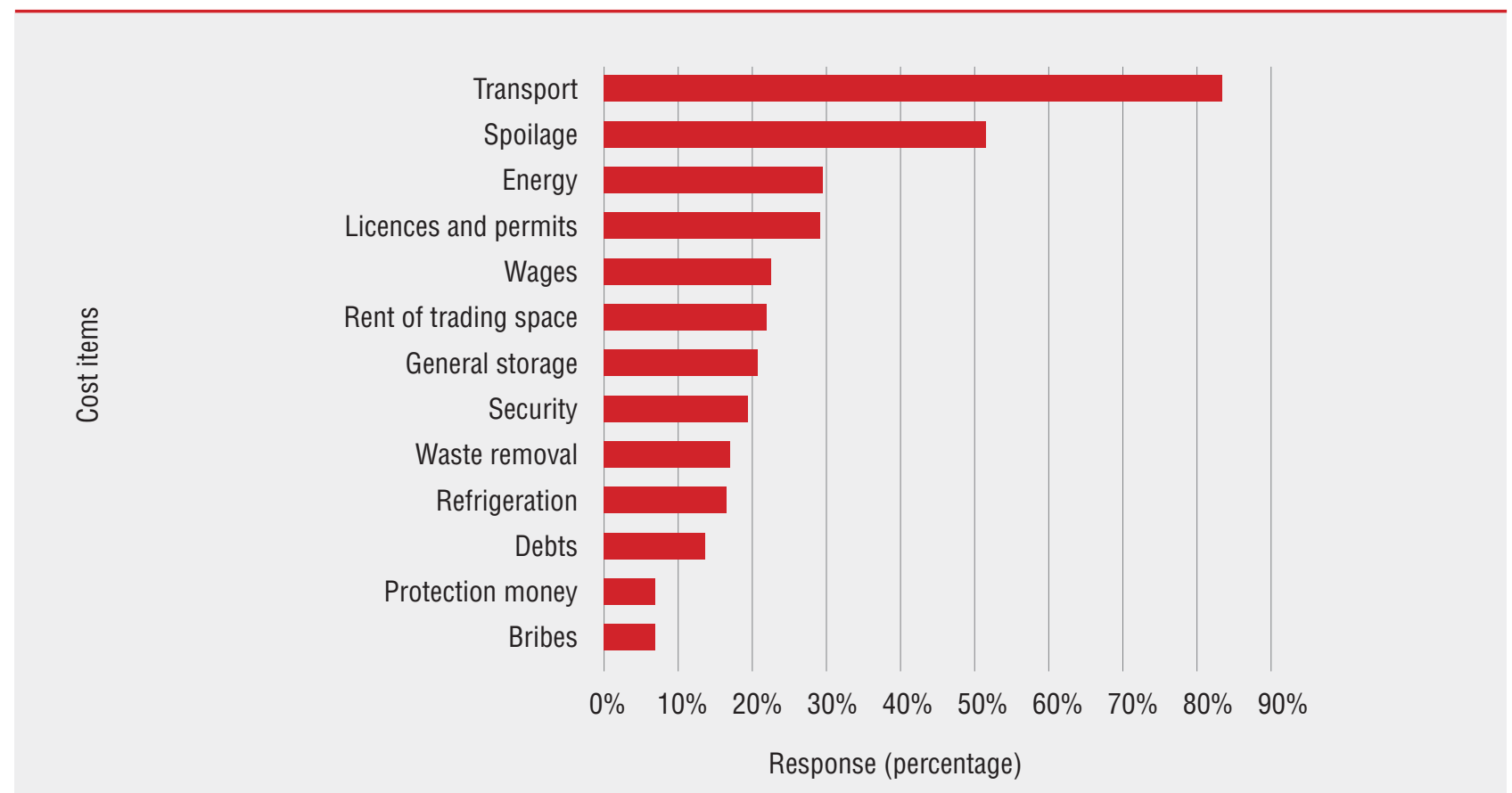

Figure 31: Cost of business operations other than stock (multiple-response question $n=1839$ )

Costs arising from spoilage came second to transportation, with more than $50 \%$ of respondents reporting losses as a result. To a large extent, the distribution of the cost of business operation is a reflection of access to infrastructure, as well as governance processes and attendant (in)security issues. For instance, the low cost recorded for refrigeration and general storage, and the relatively high cost of waste removal, might be the result of low levels of access to these infrastructural facilities. However, any attempt to navigate low access (e.g. through frequent restocking) leads to higher transport costs. The cost of governance compliance (licencing and permitting) was another item that contributes significantly to operating costs, notwithstanding the earlier assertion that licencing and permitting costs were considered affordable by many respondents. Added to the cost of compliance with governance regulations is the cost of bribes, protection money and security. These are strategies used to secure operating spaces and to engage private security to secure their wares; strategies that ultimately increase the cost of business.

\subsection{Perceived threats to viability and sustainability of informal food retail businesses}

These factors cut across many issues that have already been discussed, but are presented here in the context of their perceived threat to the survival of informal food retail businesses. Figure 32 illustrates the 15 most common threats to food retail businesses. These 'threats' can be categorised into three broad groups: those that relate to governance and security; the prevailing business environment, including financial support; and environmental factors. Of the three categories, the prevailing business environment was deemed to present particular threats to sustainability, with almost $50 \%$ of respondents regarding reliance on own finances as a threat to their businesses, and over a third of respondents citing competition from other stores.

Supply constraints were also rated as highly threatening to the sustainability of informal food retail businesses. The nature of the business environment has an influence on the pricing mechanism (near perfect competition) in the market, which means that traders cannot afford to trigger a price war or be victims of one.

Environmental factors also received a relatively high threat-tosustainability rating, considered in the context of low access to critical supporting infrastructure that exposes traders to unfavourable weather conditions, with the attendant effects of stock loss due to spoilage and loss of trading hours or days. For example, rain may displace traders without secured shelter and floods could destroy makeshift structures, causing multiple losses for traders. Due to governance and exclusionary planning codes, informal traders often operate in environmentally disadvantaged locations (e.g. near open drains) which does not augur well for the prospects of such businesses. Open drains and garbage hinder customers from accessing some food retail outlets; crowding and 
inadequate parking facilities limit access to municipal markets. Other environmental factors include air-pollution from dust or even smoke and other harmful particulates from cooking processes.

Governance issues that impact on the sustainability of the informal food retail businesses surveyed ranged from regulation, to city planning strategies, to crime. Regulation (licencing and inspections) was rated highest among the challenges posed by governance (16\%). Considered alongside city-planning strategies (12\%), harassment (a combined 14\% for government officials and police), and bureaucratic obstacles (bureaucratic processes 10\%, infrastructure deficits 6\%, planned relocations 5\%), governance-related issues become a real threat to informal food retail businesses, and were cited in almost two-thirds of all responses. The spectre of possible relocation to designated trader malls is another governance-related aspect that engenders instability and may even have a further negative consequence of limiting potential investment in existing trading structures by the traders themselves. As many of the traders lack secured shelter for their wares and trading activities, they are also exposed to social ills such as theft. This explains why a combined proportion of about $15 \%$ of respondents considered incidences of crime and gangsterism as threats to their businesses. Dealing with crime adds to the cost of doing business, evidenced by protection money being listed in the traders' cost of operations (Figure 31).

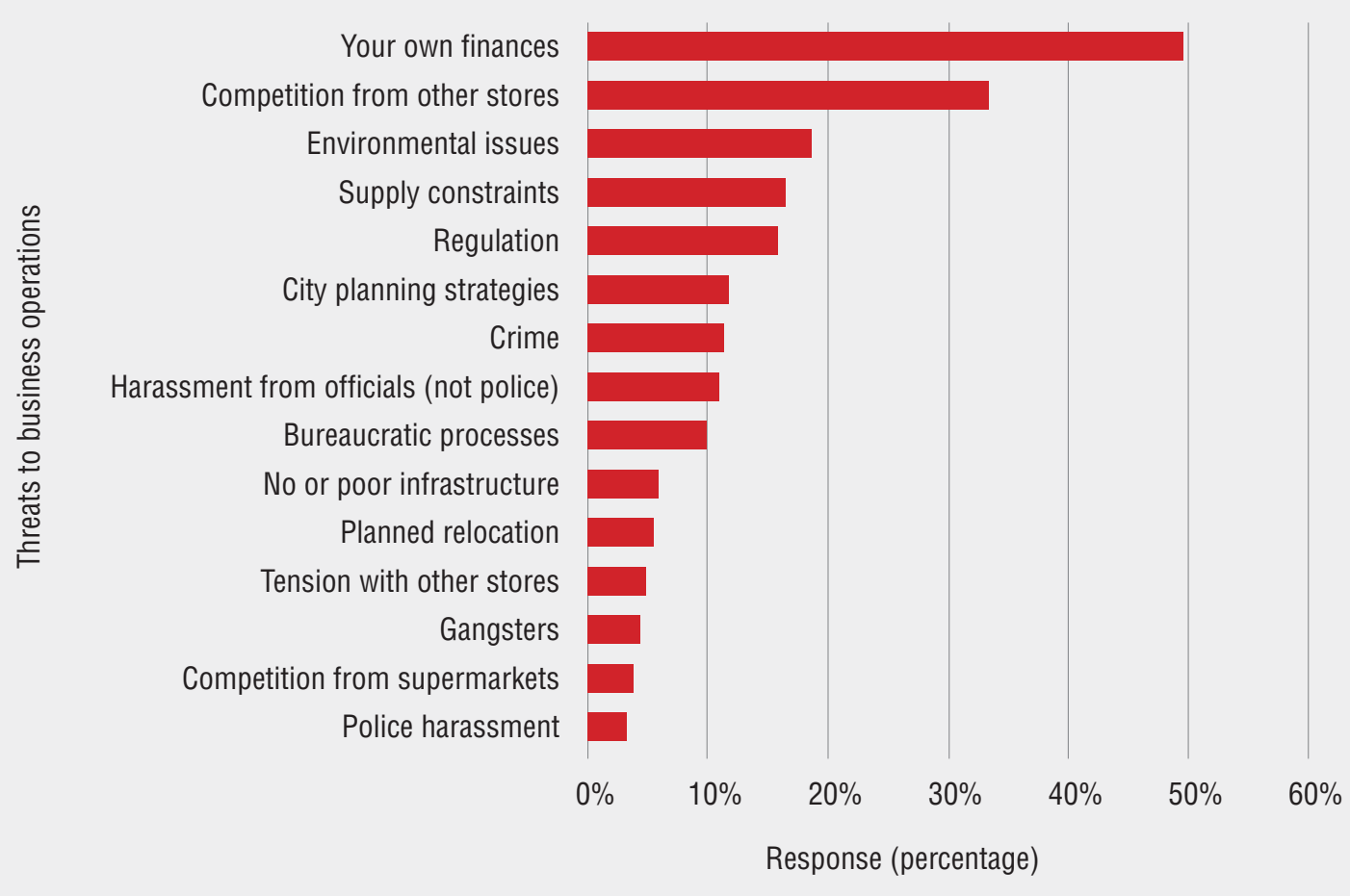

Figure 32: Perceived threats to the viability and sustainability of informal food retail businesses (multiple-response question $n=1099$ )

When asked about what could be done to enhance their trading activities, about $46 \%$ of respondents indicated that a supportive business environment was needed to improve their trade. Other business-related considerations were: increasing the general economic environment (33\%), easing supply constraints (25\%), and stable food prices $(25 \%)$.

Theoretically, a good general economic outlook will have a positive effect on informal food retailers. Unlike formal and big businesses, small informal traders might not be able to pass on or cross-subsidise erratic food-price hikes to their clients, which is why a market environment characterised by stable food prices is a desirable situation for traders. In terms of governancerelated measures, good policy (39\%) and an enabling governance environment (26\%), were considered essential to improving trade. This implies a governance environment that enables access to infrastructure and reduces the risk of doing business, including harassment by municipal law-enforcement officers and effective crime management. The challenge is that addressing these issues often requires actions at spheres of government beyond that of the city or county. Although a supportive business environment was cited by $46 \%$ of respondents, this could be considered low; the fact that not all respondents cited this poses questions about the operating environment. One possible reason for the low response to questions about the business environment could be that, for informal traders, a poor and constrained environment has become normalised.

\section{Policy-relevant synthesis}

The results of this study have policy implications in terms of governing urban food systems to mitigate food poverty and promoting enhanced nutrition status of urban residents. Governing urban food systems to achieve development imperatives is intrinsically linked to improving the livelihood activities of informal food retailers. Porter, et al. (2007) note that understanding the processes of urban governance is essential to designing interventions to address urban food poverty and secure the incomes and livelihoods of urban populations. In this regard, policy-making efforts should take cognisance of the demographic, economic, social and spatial characteristics of the urban system concerned in order to integrate the complex, competing and overlapping interests in an inclusive manner. This may require adopting pragmatic urban planning and governance 
approaches that are responsive to situated realities of place and time, but with the express goal of achieving inclusive, sustainable urban development. Doing this will also require a serious reevaluation of the informal sector's role and significance generally, to try and 'link informality to the great debates on inclusiveness, governance, pro-poor policies, enablement and [citizen] participation' (Kamete, 2012: p. 10), in planning the use of urban space.

While these research findings, which are based on a specific sampling strategy, serve only as a snapshot of a particular time and place, they show differentiated levels of engagement in informal food retail along gender lines. Women not only dominate this business sector, but also tend to do it as a longterm livelihood option; their male counterparts were generally most likely to engage in the business temporarily, or for shorter periods of time. However, men tended to enter the informal retail trade earlier than women, suggesting a traditional gender role differentiation whereby men take on the breadwinner role earlier in their lives. A more likely explanation could be pragmatic and largely informed by low employment levels in Kisumu (and potentially other secondary African cities), and may be explained by the necessity to diversify income sources at household level. These dynamics need to be understood and worked into the mainstream urban governance processes in order to promote inclusive participation in the urban economy by different groupings of urban citizens. Pursuing targeted policy framing along gender lines could be one practical and effective way to successfully implement contemporary international and national development frameworks, such as the Sustainable Development Goals (SDGs) and the New Urban Agenda (NUA), which are oriented to ensure inclusive, sustainable cities. This is important given that unemployment and poverty are characteristic features of the unfolding urbanisation processes in Africa, and their manifestation is likely to be serious in the secondary cities where weak governance structures interact with a low resource base to create uncertain urban development outcomes.

The types of food products sold, and access to appropriate infrastructure, call for responsive policy interventions through the urban governance processes in the city. The evidence showed that the categories/nature of food products sold paralleled poor access to appropriate supporting infrastructure, which has implications for livelihood security and the food safety and nutrition status of the consuming public. For example, while a lack of refrigeration and secured storage result in increased operating costs, the consuming public may be exposed to the risk of contaminated food. Quality of infrastructure certainly appears to influence the types of foods sold - in this instance, snack foods, sugared drinks, and foods associated with nutrition transition. Poor infrastructure thus contributes to the rise in non-communicable diseases. The challenge presented by low access to appropriate infrastructure and services is compounded by the very nature of informal food vending in urban environments. While the locations of retail outlets serve important spatial functions, promoting proximity and access to food, the same locational attributes expose the food products to risk of contamination. These issues are often related to complex issues of exclusionary planning that pushes informal food venders to marginal locations that invariably lack the requisite infrastructure and services (Kamete, 2012, 2013). Cooked and fresh foods are particularly delicate in this regard. While noting the multiple benefits of informal food vending, including affordability, accessibility and livelihood opportunities for the traders involved, Ahmed, et al. (2015) argue that these benefits could be cancelled out by challenges arising from lack of infrastructure and services: unsanitary environments; low access to water for cleaning and refrigeration for food preservation; inadequate public lighting that elevates insecurity, sometimes curtailing the livelihood activities of retailers. The reverse also holds true, where the promotion of an environment with access to water and sanitation and other essential infrastructure could significantly enhance livelihoods and general public health outcomes. We saw in this study that a combined proportion of about $15 \%$ of traders considered gangsters and crime as threats to their business operations, confirming how great a threat insecurity could be to informal businesses. The longer working hours of informal food retailers make them particularly vulnerable to security threats.

Governing urban food systems to reduce food poverty in secondary cities like Kisumu will entail appropriate policy design to address the above issues. Doing so will require policy interventions that appreciate the role of informal businesses in the urban economy generally, and the informal food retail sector's contribution to household food security in particular. An appraisal of the informal economy's role will then enable the sector's incorporation into the economic landscape, policy structures and programmatic interventions in city governance. The informal sector has not been considered favourably in city governance, due to the fact that authorities view the sector from the perspective of formal business logic (Kamete, 2012). Consequently, it will seem that informal businesses do not meet certain standards, such as being registered and regulated entities, operating in municipally designated spaces, or paying taxes and levies. When viewed through a formal lens, these businesses operate illegally and should not be supported. However, not only is this position untenable, it also necessitates change to reflect the complexities, realities and relevance of the sector in the urban economies of Africa. This survey found a real desire from most respondents to comply with permitting, licencing and regulation. Holding on to a position that views vendors included in this survey as illegal will suggest the authorities' lack of understanding about the livelihood strategies of the poor (key constituents), or its obsession with implementing modernist urban-planning policies irrespective of the consequences it might have on sections of the urban citizenry (Kamete, 2012). The evidence gathered during this survey has matched other evidence (Roever, 2014; Budlender, 2015), confirming that, while many informal businesses might not be formally registered, they contribute significantly to municipal revenues through the payment of taxes, VAT, tolls, rates and fees. This entitles informal traders access to support services from the municipal, county and national governments.

As evidence in this study shows, the health of an urban economy in an African city context may well hinge on the informal sector's vibrancy, given the latter's contribution to employment, household income, urban food security, and municipal and national revenue generation. The sector needs to be considered beyond a narrow view of it being a survivalist activity for the poor. Its significance is much more than that. If these contributions are acknowledged and appreciated by the city authorities, evidence emanating from case studies like this one must to be taken seriously as the basis for the re-orientation of planning and urban governance to promote inclusive, economically viable cities. The re-oriented policy environment (from hostile, modernist ambivalence to inclusive and supported) will have to foster greater collaboration to address challenges, while promoting a responsive governance regime that tackles some of the governance-related challenges the traders deemed inimical to their business operations. For this to happen, especially within the SDG and NUA frameworks, "[cities] will need to recognise, validate and support the urban working poor in the informal economy and their livelihood activities' (Chen, 
2017). This will provide the necessary policy and governance environments that will, in turn, improve the general supportive business environment that traders seek to ease their business constraints.

Another crucial policy and programmatic intervention to support informal food retailers and the informal sector generally, is in the area of finance. The fact that the majority of traders in this study were own-account workers and relied largely on their own income for financing, exposed the traders to precarious financial situations. Accordingly, supportive governance interventions should encompass targets to improve traders' access to financial support, perhaps through schemes such as revolving funds. Admittedly this is not an easy intervention, given that municipal authorities often struggle to mobilise adequate resources to deliver on some of their most basic mandates. Nevertheless, this can be done if the design and implementation of the intervention is operationalised within the true spirit of governance, involving interaction and engagement among governmental structures, the traders or their associations, activists and civil society groups (e.g. development NGOs). Given the finding that commercial banks were active, albeit on a small scale, in providing some financial support to traders, this is an additional possible strategic partner in such initiatives. The traders or their associations will have to play an active strategic role in such multi-actor engagements. Two things may be crucial in this regard. The first concerns the prevalence of conducive democratic governance structures to enable trader mobilisation by which they develop a 'voice' (Amis, 2004), which is essential for effective participation in decision making and the design of policy interventions. The second factor relates to mechanisms that capacitate traders to articulate their 'voice' in the arenas of multi-stakeholder dialogue. Good examples exist elsewhere of informal trader mobilisation to dialogue with governmental bodies and civil society groups - for example in Durban, South Africa (Skinner, 2016; Chen, 2017); and in Accra, Ghana, where informal traders have mobilised themselves into associations and collaborated with civil society groups in a relationship that resulted in the latter building the capacity of the former to dialogue and negotiate with municipal authorities to have to their interests served (Adamtey, 2014; Budlender, 2015; Chen, 2017).

Ordinarily, a regulatory regime that is both flexible and affordable will draw compliance from informal businesses. Compliance might be regarded as a guarantee of security of tenure, legitimacy and protection against harassment by municipal authorities. Thus, devising innovative regulatory regimes that recognise informal businesses, and informal food retail in particular, as a key component of the urban economy could enhance urban governance outcomes in Africa's secondary cities. As observed earlier, the informal sector's viability could have a multifaceted impact on household income, household food security, employment, and contributions to municipal government revenues. Given that these issues are the emergent challenges of urbanisation in secondary cities, it is in the interest of both municipal and national governments to shelve hitherto belligerent policies towards the informal sector, and embrace, integrate and nurture the sector to drive the socio-economic development of urban economies.

When considering the Kisumu case in the context of broader debates around the informal sector, and the informal food retail sector in particular, further evidence emerges. One such factor, which has been argued by the likes of WEIGO and StreetNet for some time, is that the differentiation between so-called formal and informal sectors is misleading, if not disingenuous.
The distinction between formal and informal is something that was frequently found to be unclear. Examples of financial support from commercial banks, formal retailers being used as wholesale-type suppliers, connections between other formal food-system actors, including importers, and other such links, reflected a wider, 'holistic' food-system economy. Informal food retailers also engaged and supported other informal-sector actors, including transport operators, waste collectors and other peripheral enterprises (e.g. bag sellers). Given the low levels of formal employment, such mutual support and networks are essential to the urban economy and the city's vibrancy. The survey in Kisumu found high levels of compliance and payment for permissions to operate, countering the often-held position, academically (in places) and from a policy perspective, of permissions avoidance and adopting deliberate strategies to avoid compliance, tax payments and other related income-collection strategies. Numerous other examples have been provided, all of which require far greater interrogation into the commonly held positions relative to the informal food retail sector. This paper has chosen to retain the binary between formal and informal in how the distinctions are made in this report, but this is informed by the current manner in which the different sectors are framed and understood.

\section{Conclusions}

This study described the nature and role of informal food retail in the food systems of Kisumu. The findings established the dominance of women in the trade, as has been reported in previous studies. It was further revealed that women not only dominated the landscape of informal food retail, but were also more likely to engage in it as a long-term livelihood strategy compared to their male counterparts, whose participation is relatively transient in nature. Governing urban food systems to reduce food poverty and promote livelihood security will entail mapping out these complex dynamics and embedding them into policy making and programmatic interventions to promote inclusive and sustainable urban development.

It also emerged that the spatial distribution of informal food retail outlets serves the important function of promoting easy access to food by a wide range of the city's population. Clients frequented food retail outlets largely due to proximity considerations, as well as mutually constituted social and economic relations such as accessing credit from traders.

If added to job/employment generation, and input to municipal and national revenue portfolio through the payment of rates, licence fees, permits, tax and market tolls, the contribution of informal food retail to the city's economy and social fabric is immense. The findings thus contribute to the growing evidence that informal businesses do indeed pay taxes, against the longheld view to the contrary. Yet the sector faced several challenges, such as lack of appropriate infrastructure and services, hostile business environment (due to regulatory harassment), and limited financial support. The traders adapted to these challenges using various strategies including frequent restocking, and the payment of bribes and protection money. However, these strategies increase the cost of doing business and might not be sustainable, thus affecting the viability of the business and the costs associated with food access for the poor. For example, adaptation by frequent restocking has high overhead costs accruing from transportation and possible product spoilage. On the other hand, the effects of poor access to infrastructure go beyond impacting the traders' livelihoods to include possible risk to consumers through food-safety concerns. We argue that, 
in a holistic assessment, the relevance of informal food retail to urban economy functioning should be appreciated and provide grounds for food-governance issues to be integrated into the policy discourse of urban governance.

The high levels of food insecurity in Kisumu are compounded by low levels of dietary diversity (see CUP Working Paper 4: The Characteristics, Extent and Drivers of Urban Food Poverty in Kisumu, Kenya). These present a long-term development challenge for Kisumu, the county and the wider region. The informal food economy is a key point of food access and its absence would precipitate far higher levels of food insecurity. The reverse argument also holds true: it is reasonable to assert that improving the informal food economy's operations could play a significant role in reducing food insecurity in Kisumu.

Programmatic policy responses must take a contextually informed, pragmatic and forward-thinking approach to planning, making local circumstances and aspirations drive the process, rather than pursuing grand, top-down (often modernist) planning codes that have historically served to perpetuate exclusion and inequality (most of which can be traced back to distinctly colonial origins). Such bottom-up programming could enjoy support for implementation if operationalised within the frameworks of higher level or global development agenda like SDGs 2 and 11 and NUA. However, and as Battersby (2017) notes, the food goal in the SDGs does not focus much on urban food insecurity. which implies that for a localised policy intervention to garner adequate traction there is a need to deliberately link it to the SDGs - in this case linking SDGs 2 and 11 (the food security and urban goals respectively), but also SDG 8 (decent work and economic growth) and SDG 1 (no poverty) - and then integrate these with the development aspirations contained in the NUA and the associated national urban plans and county plans. By doing this, food-systems governance in Kisumu could be strategically positioned to improve food security for the city's population, and support the livelihoods of traders engaged in informal food retail businesses.

\section{CUP-related reading and resources}

\section{Kisumu-related policy briefs}

Policy Brief \#1: Informal Food Retail and Food Security in Africa: Myths and Facts

Policy Brief \#2: The Importance of the Informal Food Sector in the Kisumu Food System

Policy Brief \#3: Enhancing Food Security through Urban Infrastructure and Services

Policy Brief \#4: Food Security in Kisumu: A Call for Greater Engagement in the Urban Food System

\section{Consuming Urban Poverty project books}

Urban Food Systems Governance and Poverty in African Cities

Tomatoes \& Taxi Ranks: Running our cities to fill the food gap

\section{CUP website}




\section{References}

Adamtey, N. (2014). Informal economy budget analysis: Accra Metropolis. (33). Manchester, UK.

AfDB. (2011). Transforming Africa's cities and towns into engines of economic growth and social development. Tunis.

Ahmed, S., Simiyu, E., Githiri, G., Sverdlik, A. and Mbaka, S. (2015). Cooking up a storm: Community-led mapping and Nairobi's informal settlements.

Amis, P. (2004). Regulating the informal sector: Voice and bad governance, in Devas, N. (ed). (2004) Urban governance, voice and poverty in the developing world. London: Earthscan. pp. 145-163.

Anyidoho, N.A. and Steel, W.F. (2015). Perceptions of costs and benefits of informal-formal linkages: Market and street vendors in Accra, Ghana. (35). Cambridge, MA, USA.

Battersby, J. (2011). Urban food insecurity in Cape Town, South Africa: An alternative approach to food access. (28). pp. 545561.

Battersby, J. (2017). MDGs to SDGs - new goals, same gaps: The continued absence of urban food security in the post-2015 global development agenda. African Geographical Review, 36(1), pp. 115-129.

Benjamin, S. and Bhuvaneswari, R. (2001). Democracy, inclusive governance and poverty in Bangalore. (26). Birmingham. Available at: http://www.academia.edu/download/31028337/ democracy-poverty-and-goverance-in-bangalore.pdf.

Budlender, D. (2015). Budgeting and the informal economy budgeting and the informal economy in Accra, Ghana. (5). Manchester, UK.

Cheeseman, N. (2015). Democracy in Africa and the few rotten apples. Available at: http://www.nation.co.ke/oped/Opinion/ Africa-Democracy-Politics-Research/440808-2808336xorq81/index.html [Accessed 11 April 2017]

Chen, M.A. (2017). The informal economy in African cities: Key to inclusive and sustainable urban development. Available at: https://oecd-development-matters.org/2017/04/04/theinformal-economy-in-african-cities-key-to-inclusive-andsustainable-urban-development/ [Accessed 11 April 2017]

Cirolia. L. (in press). Public Finance in Kisumu. PhD thesis under examination review (November 2018).

Clark, G. (2010). Gender fictions and gender tensions involving 'traditional' Asante market women. African Studies Quarterly, 11(2-3), pp. 43-66.

County Government of Kisumu. (2015). Economic transformation for the residents of Kisumu County. Fiscal Strategy Paper for FY 2015/2016. Kisumu.

De Soto, H. (1989). The Other Path: The Economic Answer to Terrorism. New York: Harper Collins.

De Soto, H. (2000). The Mystery of Capital: Why Capitalism Triumphs in the West and Fails Everywhere Else. New York: Basic Books.

Devas, N. (2004). Urban poverty and governance in an era of globalization, decentralization and democratization, in Devas, N. (ed). (2004). Urban governance, voice and poverty in the developing world. London: Earthscan. pp. 15-36.

ECA. (2010). Assessing regional integration in Africa IV: Enhancing intra-African trade. Adis Ababa: United Nations Economic Commission for Africa.

FAO. (2003). The informal food sector: Municipal support policies for operators. A briefing guide for mayors, city executives and urban planners in developing countries and countries in transition. Rome.

Herrera, J., Kuépié, M., Nordman, C.J., Oudin, X. and Roubaud, F. (2012). Informal sector and informal employment: Overview of data for 11 cities in 10 developing countries. (9). Cambridge, MA, USA and Manchester, UK.

International Labour Organization (ILO) (2003). Guidelines concerning a statistical definition of informal employment, in Seventeenth International Conference of Labour Statisticians (Geneva 24 November-3 December 2003), Report of the Conference (Geneva, doc. ICLS 17/2003/R.)

Kamete, A.Y. (2012). Missing the point? Urban planning and the normalisation of 'pathological' spaces in southern Africa. Transactions of the Institute of British Geographers. October/2, pp. 1-13.

Kamete, A.Y. (2013). On handling urban informality in southern Africa. Geografiska Annaler, Series B: Human Geography, 95(1), pp. 17-31.

Kennedy, G., Nantel, G. and Shetty, P. (2004). Globalization of food systems in developing countries: A synthesis of country case studies, in Globalization of food systems in developing countries: Impact on food security and nutrition. Rome: Food and Agriculture Organization of the United Nations. pp. $1-26$.

Kenya Inter-Agency Rapid Assessment (KIRA). (2014). Kenya: Inter-communal conflict by county (January-November 2014).

Kenya National Bureau of Statistics. (2013). Nyanza province multiple indicator cluster survey 2011: Final report. Nairobi.

King, R. (2006). Fulcrum of the urban economy: governance and street livelihoods in Kumasi, Ghana, in Brown, A. (ed). (2006) Contested spaces: Street trading, public space and livelihoods in developing countries. Rugby: ITDG. pp. 99-118.

Kisumu Integrated Strategic Urban Development Plan, 2013. County Government of Kisumu.

Mendez, M.A. and Popkin, B.M. (2004). Globalization, urbanization and nutritional change in the developing world, in Globalization of food systems in developing countries: Impact on food security and nutrition. Rome: Food and Agriculture Organization of the United Nations. pp. 55-80.

Mireri, C., Atekyereza, P., Kyessi, A. and Mushi, N. (2007). Environmental risks of urban agriculture in the Lake Victoria drainage basin: A case of Kisumu municipality, Kenya. Habitat International, 31(3-4), pp. 375-386.

Mwitwa, J., Sibajene, M., Chipoya, G.C. and Namiluko, Y. (2016). City region food system situational analysis, Kitwe, Zambia. Rome.

Obeng-Odoom, F. (2013a). Governance for pro-poor urban development (reflections on the book Governance for propoor urban development: Lessons from Ghana). Urbani izziv, 24(2), pp. 156-158.

Obeng-Odoom, F. (2013b). Governance for pro-poor urban development: Lessons from Ghana. London: Routledge.

Opiyo, P., Obange, N., Ogindo, H. and Wagah, G. (2018). The Characteristics, Extent and Drivers of Urban Food Poverty in Kisumu, Kenya, Consuming Urban Poverty Project Working Paper No. 4, African Centre for Cities, University of Cape Town.

Porter, G., Lyon, F. and Potts, D. (2007). Market institutions and urban food supply in West and Southern Africa: a review. Progress in Development Studies, 7(2), pp. 115-134.

Roberts, B.H. (2014). Managing systems of secondary cities: 
Policy responses in international development. Brussels: Cities Alliance/UNOPS. Available at: http://www.citiesalliance.org/ node $/ 4978$.

Roever, S. (2014). Informal Economy monitoring study sector report: Street vendors. Cambridge, MA, USA: WIEGO.

Setšabi, S. (2006). Contest and conflict: Governance and street livelihoods in Maseru, Lesotho, in Brown, A. (ed). (2006). Contested spaces: street trading, public space and livelihoods in developing countries. Rugby: ITDG. pp. 131-152.

Skinner, C. (2016). Informal food retail in Africa: A review of evidence. (2). Cape Town.

Skinner, C. and Haysom, G. (2016). The informal sector's role in food security: A missing link in policy debates? (44). Cape Town.

Steel, C. (2013). Hungry city: How food shapes our lives. London: Random House.

Steel, W.F., Ujoranyi, T.D. and Owusu, G. (2014). Why evictions do not deter street traders: Case study in Accra, Ghana. Ghana Social Science Journal, 11(2), pp. 52-76.

Steyn, N.P., McHiza, Z., Hill, J., Davids, Y.D., Venter, I., Hinrichsen, E., Opperman, M., Rumbelow, J., and Jacobs, P. (2013). Nutritional contribution of street foods to the diet of people in developing countries: a systematic review. Public Health Nutrition, 17(6), pp. 1363-1374.

United Nations Economic Commission for Europe (UN-ECE). (2010). Measuring quality of employment: Country Pilot Reports. United Nations, Geneva.

UN-Habitat. (2006). Kisumu urban sector profile. Nairobi.

UN-Habitat. (2009). Planning sustainable cities: Global report on human settlements 2009. Nairobi.

UN-Habitat. (n.d.) Kisumu development strategies (2004-2009): Lake Victoria region city development strategies for improved urban environment and poverty reduction. Kisumu.

Wiskerke, J.S.C. (2015). Urban food systems, in De Zeeuw, H. and Drechsel, P. (eds). (2015). Cities and agriculture: Developing resilient urban food systems. London and New York: Routledge. pp. 1-25. 
